\title{
LAS MARCAS DE LOS SUJETOS EN EL ESTADO. LOS TRABAJADORES DE LA ECONOMÍA POPULAR Y LAS POLÍITICAS PÚBLICAS EN LA ARGENTINA RECIENTE
}

\author{
María Antonia Muñoz (•) \\ Universidad Nacional de La Plata - \\ IDIHCS/CONICET
}

\begin{abstract}
RESUMEN
El presente artículo analiza la evolución de las políticas públicas orientadas a resolver los problemas que se generaron en el mercado laboral (desocupación, informalidad y pobreza) durante las últimas décadas en Argentina. Se problematizan las interacciones entre actores claves (gobiernos y organizaciones) en la formación de las mismas, prestándose especial atención a dos programas; el Programa de Ingreso Social con Trabajo (2009) y el de Transición al Salario Social Complementario (2016). Entre las fuentes primarias se analizan datos estadísticos de carácter nacional (provenientes de diferentes fuentes oficiales y privadas), entrevistas en profundidad a referentes de las organizaciones y análisis de discurso de las políticas. Se muestra como estas complejas interacciones colaboraron con la ampliación, consolidación y transformación de un nuevo sujeto/objeto de aquellas políticas: «los trabajadores de la economía popularm. Se concluye con la necesidad de ver las potencias transformadoras a la vez que los límites que las políticas conllevan.
\end{abstract}

\section{PALABRAS CLAVE:}

trabajadores de la economía popular y social, políticas públicas, demandas, organizaciones populares, Salario Social Complementario.

\footnotetext{
(•)E-mail: mariaantoniamunoz@gmail.com
}

\section{ABSTRACT}

The article studies the evolution of public policies related to unemployment, informality, and poverty during the last decades in Argentina. The interactions between key actor as governments and organizations are problematized, with focus on two programs: Social Income with Work -2009-and Social Complementary Wage -2016. Primary sources are statistical data, interviews with social 85 leaders and discourse analysis to public policies. It is shown how these complex interaction collaborated to increase and also to the consolidation of a new subject and, at the same time, object of those: workers of the popular economy. It is concluded with the need to see the potentiality for positive social change but also the need to analyses the limits of these programs.

\section{KEY WORDS:}

workers of popular economy, policies, demands, popular organizations, Social Complementary Wage. 
Los trabajadores de la economía comenzaron a tener relevancia en la última década en Argentina producto de la creación de la Confederación de los Trabajadores de la Economía Popular (CTEP) en el año 2011. No obstante, su punto de máximo reconocimiento ha sido a partir de la inscripción de los mismos en la letra de la reciente Ley de Emergencia Social. Esta fue sancionada por unanimidad parlamentaria en el año 2016.

En este contexto, la expansión de los trabajadores de economía popular ha sido tematizada desde diferentes nudos problemáticos: desde las dificultades del mercado de trabajo para eliminar la informalidad y la precariedad laboral, desde la expansión de las políticas sociales y desde las acciones colectivas de las organizaciones sociales que los reivindican.

Cierta literatura ha señalado que, la transformación de los mercados laborales desde la apertura democrática hasta la actualidad, se ha caracterizado 
por la persistencia de la informalidad, la segmentación y la precariedad laboral (Arakaki, 2017; Arango et al, 2017; Neffa, et al, 2010). Los autores señalan que, a pesar de la creciente formación de empleo después de la convertibilidad, la informalidad y su impacto sobre la pobreza es un fenómeno que persiste (Beccaria y Groisman, 2008). Algunos estudios imputan las causas de la misma, así como de la desigualdad en la distribución del ingreso, a las características estructurales de la economía y la segmentación de los mercados laborales (Lavopa, 2007; Graña, 2013). Pero estaos estos estudios no se detienen a analizar el peso de las políticas públicas en la transformación de la estructura, en los cambios en torno a lo que se reconoce como trabajo. Tampoco toma en cuenta la importancia de las acciones colectivas como factor de transformación de la propia estructura que cuestiona. Es así que la economía popular está ausente como categoría de análisis de estas investigaciones que explican la precariedad laboral. Frente a estas limitaciones, parte del debate refiere al alcance de las políticas públicas, en particular las sociales, como instrumentos para combatir las consecuencias negativas de este tipo de mercado de trabajo (Arcidiácono y Zibechi, 2017; Danani y Hintze, 2014; Pautassi y Gamallo, 2017; Pautassi y Zibechi, 2010).

En general, se destaca que las políticas públicas se transformaron hacia fines de los noventa, adquiriendo masividad en las transferencias de ingresos a grupos vulnerables como los desocupados. El plan Jefes y Jefas de Hogar (PJyJH) en el año 2002, el programa Familias para la Inclusión Social en el 2005, la Asignación Universal por Hijo (AUH) y el Programa de Ingreso Social con Trabajo (PRIST) en el 2009 fueron estudiados como herramientas de distribución del ingreso secundario para mejorar en la calidad de vida de los deciles más bajos de la pirámide social (Cruces y Gasparini, 2008; Goldbert, 2004; Groisman, 2016; Trujillo, 2017). Se suele destacar que los gobiernos después del 2003 y hasta el 2015 intentaron responder a la estructura de riesgo transformada con las políticas públicas producto de los problemas de mercado de mencionados más arriba. No obstante, no existió un correlato con una respuesta institucional acorde que avanzara "sobre una arquitectura del Estado de Bienestar" (Pautassi y Gamallo, 2017; 31). Estas iniciativas desde el Estado no disolvieron los obstáculos generados por los mercados laborales, ni rompieron con la segmentación en materia de acceso a salud, a la educación y a un nivel de ingreso mayor al salario mínimo (Hopp, 2016; 2017).

Antia (2017) sostiene que la literatura especializada ofrece diferentes razones para explicar la expansión de esta política social. Mientras algunos autores muestran que se trataron de procesos de "difusión» regional de las políticas de 
transferencias condicionadas otros argumentan que las coaliciones políticas requerían del apoyo de los movimientos sociales que eran favorecidos con estas políticas. Ahora bien, ningún análisis pone el peso en la continuidad de las políticas sociales aun cambiando el signo político del gobierno como ocurrió en Argentina después del 2015. Tampoco se especifican las luchas históricas en torno a las re significaciones acerca del trabajo y los derechos asociados a él.

El presente artículo se centra en una vacancia en los estudios recientes asociados a esta intersección entre las políticas públicas, organizaciones y la emergencia de los trabajadores de la economía popular. En este sentido, se analizara el rol de las organizaciones sociales como parte de los procesos políticos que impactaron sobre la constitución de la economía popular como problema público y las políticas asociadas a éste. Se sustenta que la construcción de un Estado de Bienestar depende de las potencias transformadoras de la interacción entre las políticas públicas y los colectivos sociales.

Las políticas públicas son el resultado de las luchas de los diferentes colectivos que no solo presionan por la distribución secundaria del ingreso nacional sino por los alcances del proceso de mercantilización o des mercantilización social (Esping Andersen, 1993; Grassi, 2003). Así, éstas no solo intervienen en las condiciones de vida modificando o reproduciendo las condiciones de desigualdad (Adelantado et al, 1998; Cortés y Marshall, 1991; Soldano y Andrenacci, 2005). También transforman los límites de lo público y lo privado, legitiman lo que puede ser parte de la esfera mercantil y lo que tiene que ser otorgado por el Estado como fundamento de los derechos. Pero para ello es necesario tener en cuenta no solo a las políticas sino a las relaciones de fuerza que se establecen entre diferentes colectivos.

Aquí se otorgara una mirada procesual donde las políticas fueron objeto de las re significaciones y transformaciones que hicieron los sujetos colectivos de las mismas, aunque también se ofrecerá una mirada estática (después del 2016) en la cual se pueden encontrar en las propias políticas las marcas de la subjetividad de aquellos. De esta manera, se discute la idea de que la política social se reduce a la reproducción del orden social o que solo se orienta a contener la conflictividad social. En cambio se sustentará que éstas son producto de la condensación de las luchas pasadas y aperturas a futuros posibles, sobre todo, en relación con la distribución del ingreso, las luchas por los sentidos del trabajo y del bienestar en general. En particular, se argumentara cómo las organizaciones fueron mostrando que las políticas deben reconocer a los "beneficiarios" o "efectores sociales" como "trabajadores de la economía popular", buscando (todavía sin éxito) poner en el centro de la escena que el 
bienestar social no tiene que estar ligado al lugar que ocupa la persona en los mercados. La propuesta de las organizaciones que pretenden representar a esos trabajadores es que, debe ser el Estado el que transforme el proceso de satisfacción de necesidades, ampliando las concepciones en torno a los trabajadores y sus derechos. Aquellas no pueden ser responsabilidad de los individuos, ni de su nexo monetario mercantil, ni de la estructura productiva. Desde este punto de vista, se prestará especial atención a las potencialidades en relación con la formación de colectivos y sus derechos y a las luchas en torno a los sentidos sociales y económicos que emergen de esta relación.

El artículo rodeará algunos nudos problemáticos. En primer lugar, se desarrollaran las políticas asociadas al problema del desempleo y la pobreza en Argentina. Para ello se prestara atención a los niveles de protección social, la generación de trabajo autogestionado y/o de la economía popular debilidades (asociado al cooperativismo o no) y los contextos socioeconómicos y simbólicos más amplios en los cuales se insertan las políticas. En segundo lugar, se analizara el pasaje de las organizaciones de los "trabajadores desocupados" a "los trabajadores de la economía popular", el perfil de sus organizaciones, las demandas corporativas y políticas, las alianzas y el reconocimiento social que han logrado en el tiempo. En tercer lugar, se mostrará cómo las contradicciones en las políticas públicas sivieron como potencias que fueron y son posibles de ser explotadas políticamente por las organizaciones. Antes de avanzar sobre esto se realizará un acercamiento sobre la "economía popular" a partir de los debates que informan a (pero también son producidos por) las políticas públicas, los gobiernos y las organizaciones sociales ¿Son los trabajadores de la economía popular la expresión de las fallas de la economía o son la norma de un capitalismo que prescinde cada vez más de la relación asalariada como forma de acumulación y sostenimiento en el tiempo?¿Qué solución merece desde la comunidad política (y por derivación desde las políticas públicas)?

Para lograr lo dicho se adoptó un enfoque cualitativo y cuantitativo, ambos solidarios con la teoría del discurso. Esta parte del supuesto de que los sistemas de prácticas de sentido dependen de exteriores discursivos que, a la vez que los constituyen, potencialmente también los subvierten. Además caracteriza a las relaciones sociales a partir de su contingencia, historicidad, poder y primacía de la política. Por ello aquí se propone analizar las marcas de los sujetos colectivos en el Estado a partir de las dimensiones de las políticas públicas y de la acción colectiva como dos regímenes que se condicionan y subvierten mutuamente.

Para analizar la primera se investigó no solo el tratamiento nominativo de la población objetivo de las políticas, sino los niveles de cobertura y protección 
social (en el caso de que estuviera involucrada), así como el impacto sobre la desocupación y la informalidad. Para analizar la dimensión de la acción colectiva se tuvo en cuenta las organizaciones sociales que interactuaron con las políticas públicas a partir de: la presentación en el espacio público de sus demandas y reivindicaciones asociadas al trabajo, las relaciones de enemistad y alianzas, los niveles de organización, las capacidades de negociación y participación en la formulación de las políticas, así como de veto o amenaza a la estabilidad política. Para esto se analizaron entrevistas en profundidad a referentes de las organizaciones y profesionales del Ministerio de Desarrollo Social y de Trabajo, Empleo y Seguridad Social. ${ }^{1}$ Además, se recurrió a datos estadísticos para analizar ciertas dinámicas del mercado de trabajo y del impacto de las políticas públicas. Es necesario aclarar que no existen fuentes oficiales estadísticas en torno a la economía popular, por lo que se construyen aproximaciones en torno a diferentes bases de datos y fuentes secundarias.

\section{LOS TRABAJADORES DE LA ECONOMİA POPULAR ¿EXPRESIŌN DE LA NEGATIVIDAD DEL SISTEMA O POTENCIA EMANCIPATORIA?}

En Argentina, las caracterizaciones de economía popular y sus trabajadores nacen al calor del debate académico pero sobre todo político durante los últimos años. Lo que viene a poner en cuestión esta categoría es el estatuto del trabajo y los derechos asociados a él. Más que definiciones precisas, este debate deja preguntas abiertas que, como se analizará en las últimas secciones del presente trabajo, se intensifican en los últimos años a partir de la sanción de la Ley de emergencia Social.

No obstante, desde la sociología del trabajo se viene poniendo en cuestión la interpretación del mundo laboral centrada en la imagen de la relación asalariada asociada al modelo fabril propio de la etapa fordista - keynesiana. (Bialakowsky y Hermo, 2015; Denning 2011). El problema de asociar el trabajo solo al empleo asalariado y formal no solo reduce el campo de estudio sino que invisibiliza otras realidades y soluciones en materia de políticas públicas. La teoría crítica latinoamericana ha puesto de relieve que, lo que se considera la normalidad del capitalismo mercantil y sus formas de trabajo asalariadas, en nuestra región no lo son ni lo fueron (Quijano, 2000). Dicho de otra manera, la relación asalariada formal y privada no representa la mayor parte de la fuerza de trabajo. Además, a la luz de los cambios de las últimas décadas en materia económica, autores como Antunes (1999) o De la Garza (2011) hace 
ya más de una década que comenzaban a señalar la necesidad de ampliar el concepto de trabajo y las formas en que los trabajadores se organizan. En general, las discusiones giran en torno a que existe un nuevo funcionamiento de la economía global que ha transformado la centralidad del trabajo asalariado (Altvater, 2014: Nun, 2010). Pero ya sea por el hecho de que las sociedades latinoamericanas nunca fueron, no lo son o nunca serán asalariadas, la centralidad del "trabajo" y, por tanto, qué derechos deben asociarse a él, sigue siendo una pregunta abierta.

En el mundo, los debates en torno al rol del Estado y la capacidad de las políticas públicas de afrontar la nueva estructura de riesgos sociales, han impulsado una serie de respuestas. La renta básica universal, las propuestas de "job guarantee" y la economía social y solidaria han sido propuestas de solución a la crisis de la sociedad asalariada sobre todo en el caso europeo. El contexto específico se orienta a la protección y la cohesión social con un fuerte componente de valores de "solidaridad" como fuerza inercial o path dependency del Estado de Bienestar típico de la región. En el caso latinoamericano, lo que más se ha desarrollado fueron las políticas asociadas a la economía social y solidaria, no solo desde el debate académico, sino desde los gobiernos post neoliberales (Coraggio, 2017; Hintze, 2010). En este breve artículo es imposible repasar el debate con todas sus aristas pero se prestará atención a algunos elementos importantes. En particular las dimensiones problemáticas que han logrado inscribir en el espacio público las organizaciones y las políticas públicas.

Existen ciertos puntos de consenso. El primero es en torno a quienes no forman parte de este universo: los "trabajadores asalariados formales" (Maldovan et. al 2017). Esto son quienes están «integrados" socialmente a partir de dos vías: la participación en la distribución primaria del ingreso (salarios) y la secundaria (acceso garantizado a derechos y protecciones por su condición de trabajadores reconocida por el Estado). El segundo elemento de consenso es que la economía popular se organiza alrededor de trabajadores que no intercambian su fuerza de trabajo por un salario sino que es su propia auto explotación la que es el principal factor de producción (lo que supondría la existencia de un trabajo pago junto con uno excedente, no remunerado) (Icaza y Tiriba, 2004). Luego de estas anuencias en torno a lo que hace al universo de estos trabajadores, solo vienen las diferencias.

Podríamos, por motivos de extensión, proponer dos grandes formas de acercarse al problema de estos trabajadores. La primera forma refiere a la economía social y solidaria (ESS) que se presenta como alternativa al capitalismo y que tiene como centro al trabajo autogestivo y al cooperativismo. El segundo 
enfoque es el de la economía popular (EP), que es desarrollado sobre todo en los últimos años en Argentina por impulso político de las organizaciones sociales, aunque también ha sido motivo de discusión académica.

Para Coraggio, la EP refiere a un conjunto de actividades realizada por trabajadores sobre la base de las unidades domésticas, donde su principal fuerza productiva son, justamente, las capacidades de trabajo de sus miembros (Coraggio, 2016). Estos no se orientan hacia la acumulación ni a la obtención de ganancias sino a la de los medios para la reproducción de sus vidas. Esto distingue esta economía del sector "informal», el cual se comprende solo a partir de su relación con el sector formal y la lógica de comparación es la referencia a la empresa capitalista, el crecimiento continuo y el valor. La EP no representa una alternativa al capitalismo. Suele no estar estructurada y subordinada a aquel. Frente a esta, la que hay que estimular es la ESS, la cual posee elementos transformadores frente a aquel. Esta línea de pensamiento sostiene que se trata del conjunto de experiencias que están asociadas al trabajo colectivo y autogestivo, mercantil y no mercantil, con apoyo público o no, pero que por sus valores de solidaridad puede ser el camino hacia la emancipación. No refiere al problema del empleo a partir de la solución del crecimiento con trabajo asalariado industrial. El componente utópico que plantea esta forma de acercarse al problema se basa en las potencialidades (es decir, en termino de presentes posibles de ser transformados y transformadores) del trabajo asociativo, cooperativo y autónomo. Este opone a la concepción «mercantilista», el trabajo como valor en sí mismo (Hintze, 2010; Hopp, 2017).

Este grupo de reflexiones se centra en el trabajo de autogestión colectiva en tanto experiencias que contienen valores de solidaridad fuera y en contra de las lógicas de ganancia capitalistas y permiten proponer gérmenes de transformaciones futuras. Cooperación, autonomía y gestión democrática son los pilares de este esquema. Empresas recuperadas y cooperativas son en general los objetos de estudio. Las experiencias más espontáneas, desorganizadas, cuentapropistas y micro empresas quedarían al margen de la ESS y estarían más asociadas con el trabajo precario.

Los autores que optan por referir a la EP no ponen tanto el acento en los valores autogestivos o solidarios sino en las estrategias transformadoras que generan tanto la distribución del ingreso primaria y secundaria como la disputa por el Estado y la formación de derechos.

Las relaciones de la exclusión y/o la subordinación con la economía de mercado sobre determinarían a las experiencias incluso de la ESS y solo la capacidad política del Estado puede transformar las barreras de ingreso al mercado 
de trabajo, pero sobre todo poner límites a la desvalorización del mismo y los productos de la EP así como a las formas de apropiarse del excedente (Arango et al., 2017; Pérsico et al. 2017) La EP, explica Narodowski (2013), "no se caracteriza por realizar intercambios de productos fuera del mercado, ni por construir socialmente el valor de las transacciones fuera del precio de mercado, tampoco se caracteriza por surgir de relaciones interpersonales específicas, sólo está definido por no tener patrón, por la baja productividad y por no realizar un proceso de acumulación. Son simplemente personas o colectivos que desde una lógica mercantil, compran insumos y le venden al mercado (a las empresas formales, a otros colectivos similares o a los consumidores directamente); los precios están sujetos a la competencia y dependen del lugar que ocupa cada uno en la cadena de valorn (p.104) En muchos casos están obligados a vender a bajo precio, incluso aumentando la plusvalía de las unidades económicas que se manejan con lógicas capitalistas y que descentralizan en la EP para obtener ganancias mayores (Bonora 2001).

En síntesis, suponen unidades productivas de bajo capital y en general baja productividad, de auto explotación laboral, organizadas para el autoconsumo, con un pobre excedente, muchas veces impulsadas centralmente con bajo el financiamiento del Estado. Bajo esta definición entran las formas asociativas formalmente constituidas, (por ejemplo cooperativas, o las federaciones de las mismas) las unidades productivas de trabajo colectivo no formales, en general de origen doméstico, no registrados, pero también los trabajadores por cuenta propia, no colectivizados, los colectivos de usuarios y consumidores. ${ }^{2}$ Lo que en todos los casos se pone en evidencia es que la EP está en condiciones de exclusión, invisibilización y subordinación con el capitalismo, pero que a la vez suponen un proceso de producción de riqueza y trabajo. En el centro de las reflexiones sobre la EP, aun en las definiciones más economicistas, lo que existe es el señalamiento de actividades humanas definidas por la falta: no tienen trabajo formal, no tienen salario, no tienen derechos. Pero esta falta tiene un reverso positivo (el trabajo) y las posibilidades del "devenir otro".

En este sentido, Hintze (2010) sostiene esta idea de la potencialidad como aquello que "está en lo posible y aun incipientemente en acto, a la vez que refiere al poder y a la fuerza que requiera su construcción" (p.16). Pero como señala Gracia (2015), si bien estas experiencias abren espacios de experimentación colectiva de prácticas de innovación social, la potencia no puede disociarse de las estrategias y procesos de articulación que suponen relaciones de poder y construcción de hegemonía. En el mismo sentido señala Álvarez Fernández, (2016) muchas de las características de la economía popular 
deben ser pensadas no como precondiciones sino como apuestas y procesos que dan cuenta de la capacidad de los sectores populares de construir estos ámbitos laborales y desarrollar estrategias.

Este es un espacio donde se cruzan experiencias políticas y de trabajo colectivo, procesos de lucha y de producción espacial que en sí mismas cuestionan la separación entre lo político, lo social y lo económico (Gago y Mezzadra, 2015). A continuación se discutirá como las políticas públicas se transformaron. En una primera etapa pasaron de tramitar la desocupación como problema social secundario implementando principios asociados cubrir el límite de necesidades básicas. En una segunda pasaron a reconocer los límites del mercado laboral y la necesidad de promover empleo pero con fuertes limitaciones. A la vez se analizara como estas políticas fueron un marco de oportunidad para la formación de un conjunto de organizaciones que pasaron de la denuncia (de la exclusión de la sociedad asalariada) a la propuesta (de inclusión a partir de reconocerlos como trabajadores).

En particular, se verá como las políticas públicas permitieron la institucionalización de un circuito de funcionamiento de la economía popular asociada a la subsistencia por diversos canales: a través del incentivo monetario, legal o simbólico de formación de emprendimientos colectivos (Trabajar I, II y III y PJyJH) y luego de cooperativas (Manos a la Obra, PRIST), aunque también a partir de transferir ingresos a los hogares de estos trabajadores (AUH) y de la generación de un conjunto de organismos e instituciones que dieron un marco de ampliación al discurso sobre la "economía social y solidaria» como alternativa para la inclusión social. Esto permitió que las organizaciones sociales fueron transformando sus reivindicaciones y presionando en la puja distributiva y de la ampliación de los derechos. Como se describirá, el pasaje de beneficiarios pasivos a trabajadores desocupados a trabajadores de la economía popular fue inscripto en la letra de la ley. Veamos.

\section{LAS POLÍTICAS TRANSFORMADORAS Y TRANSFORMADAS}

La implementación de programas públicos de transferencias condicionadas, tanto los que obligaban a una contraprestación laboral como a los asociados a la salud y la educación, crecieron desde los noventa en adelante en todo América Latina (Cechini y Madariaga, 2011; Stein, 2017). Estos fueron en parte recomendaciones de organismos internacionales con el objeto de combatir la pobreza y la indigencia que generaba los desajustes de los mercados 
laborales (Manzano, 2013). En Argentina, se destacan tanto por el número de hogares y personas afectadas como por el gasto social generado, los siguientes programas: el plan Jefes y Jefas de Hogar (PJyJH) iniciado en el año 2002 y finalizado en el 2005, el Plan por la Inclusión Social (PRIS) iniciado en el 2005 como sucesor del anterior (y finalizado en el 2010), la Asignación Universal por Hijo (AUH), y el Programa de Ingreso Social con Trabajo (PRIST) que se crearon en el año 2009 y continúan hasta la actualidad (2018). Todos estos programas inyectaron una cantidad importante de recursos financieros a sectores que no podían acceder vía salario a la canasta básica.

En el caso del PJyJH, las transferencias se constituyeron en el principal componente de ingreso de los hogares de los primeros deciles de la pirámide social producto de la marcada desocupación. Nótese que a un año después de su implementación, las transferencias del Estado a los hogares del primer decil representaban más del 30\% del ingreso, mientras que el 15\% para el segundo. (Trujillo y Retamozo, 2017). Siete años después, la implementación de la AUH se realizó en otro contexto. El peso de los ingresos laborales originados en el empleo registrado como en el no registrado fueron las principales causas del ingreso de los hogares. En el 2003, la fuente de ingresos asociada con los salarios registrados era del $42 \%$, en el 2014 alcanzó al 50\%. No obstante, las transferencias estatales siguieron siendo muy significativos para esos hogares puesto que para los dos primeros deciles representaron el $15 \%$ y el $6 \%$. Para el 2014 se registraban 3.348.032 niños y adolescentes bajo la AUH, y aproximadamente el $27 \%$ del total de la población objetivo se encontraba cubierta (Bustos y Trujillo, 2014).

Además, abrirían el juego de la significación en torno al debilitamiento de la sociedad asalariada como eje del Estado de Bienestar y la emergencia de la «nueva cuestión social» (Cortés y Kessler, 2013). La misma se caracterizó por la emergencia masiva de la exclusión del mercado laboral tradicional, la individualización y la desafiliación sindical, la territorialización y la segregación socio espacial. En este contexto, los mecanismos para garantizar un piso mínimo para la subsistencia de una parte de la población se concentró en dichos programas. Si bien el PJyJH y la AUH fueron los más notorios en cobertura, en los noventa otros programas fueron antecedentes de estas políticas orientada a los sectores excluidos del mercado de trabajo.

A continuación se analizaran el tipo de programas, el tipo de ingreso, el impacto socioeconómico sobre la población, sobre el empleo y sobre la formación de emprendimientos con mayor o menos institucionalización. Se prestara atención a la dimensión de "nominación" y las oportunidades ofrecidas para la formación de organizaciones y la creación de nuevas formas de significación del trabajo. 
Es importante aclarar que los contextos de implementación son importantes. Se puede describir un antes y después de la crisis del 2001 y 2002. En términos generales, el periodo previo fue de contracción y concentración mientras que el posterior fue de crecimiento y distribución en materia de creación y apropiación del excedente nacional (Bona, et al. 2012). Por ello, es posible distinguir diferentes etapas de las políticas hacia los desocupados o trabajadores no formales que podrían nominarse como asistencialista frente a otra más laboralista. La tercera etapa se analizará en las secciones siguientes.

\subsection{DE LA GESTIÓN DE LA INDIGENCIA A LA GESTIÓN DE LO PRECARIO}

Los planes "Trabajar" I, II y III, se crearon en el año 1996 en adelante con financiamiento del BID y como impulso de políticas sociales focales hacia el creciente problema de la pobreza (27.9\%) y desocupación (17.2\%). La población que era objetivo del programa eran los "trabajadores desocupados" y una vez involucrada en el programa «beneficiarios". El mismo se pretendían como ayuda monetaria no remunerativa lo suficientemente baja como para generar focalización mediante la autoselección. Dicho de otra manera, las personas bajo la órbita de estos programas tenían que trabajar 6 horas a cambio de un ingreso de 160 pesos y considerando que el SMVM era de 200, esos "desocupados" persistirían en la búsqueda de otro trabajo. La ejecución de estos proyectos debía estar a cargo de organismos públicos (de cualquier nivel de gobierno) y de asociaciones no gubernamentales. Estas organizaciones adquirían el compromiso de proveer los materiales necesarios para la realización de los proyectos y brindar el personal técnico necesario. El programa financiaba la mano de obra específicamente para la realización de proyectos comunitarios orientados a satisfacer necesidades socialmente relevantes de la población con menores recursos. Así las obras de infraestructura y servicios municipales fueron las principales tareas dentro de los proyectos (Bertranou, et al, 2007). Las organizaciones se fueron profesionalizando en las estrategias de generación de los proyectos que contenían una compleja y elevada cantidad de detalles (Manzano, 2013). Además, en caso de aprobarse el proyecto, el organismo sería el responsable de garantizar los resultados. La relevancia de este programa fue que generó los marcos institucionales para la acción colectiva. Si bien un porcentaje menor estaba en mano de las organizaciones sociales de "trabajadores desocupados" y la mayoría se derivaba a los municipios cuyos intendentes apoyaban al gobierno, las organizaciones de "trabajadores desocupados" crecieron al calor de estos recursos (Svampa, 2005; Muñoz, 2005). 
Este programa desaparece en el año 2002 producto de la aparición del Jefes y Jefas de Hogar. ${ }^{3}$ Por ese entonces, los niveles de desempleo (21,5\%), pobreza (37,9 \%) e indigencia (15,2\%) eran inéditos en la historia Argentina y la conflictividad social muy alta. Si la cantidad de personas comprendidas en el Trabajar alcanzo a 271.000 (Roconi, 2002), este llegó a 2.095 .590 personas en el año 2003. La masividad obligó a aumentar el presupuesto, el cual alcanzó casi el 1\% del PBI (Neffa et al., 2008). Hay que tener en cuenta que en general estos programas en el resto de América Latina alcanzaron medio punto del PIB (CEPAL, 2017). Además, la desigualdad del ingreso medido por el GINI disminuyo de 0.56 a 0.53 entre 2002 y 2003 (Trujillo y Villafañe, 2011)

A pesar que continuaba con la retórica asistencialista de nominación de «beneficiarios", el gobierno enmarcó al mismo en el del derecho a la inclusión social y la universalización. ${ }^{4}$ El objetivo declarado era brindar ayuda económica a jefes y jefas de hogar en situación de desocupación con hijos de hasta 18 años de edad, con el fin de garantizar ese derecho. Por presiones de la Iglesia en la Mesa de Diálogo Nacional, el PJyJH se amplió a jóvenes en condiciones de presentar una declaración jurada sobre su condición de desempleados y a los adultos mayores en condiciones de presentar una constancia de no cobro de beneficio previsional.

Ambos tuvieron la misma característica. No se trataban de transferencias por la condición de desempleado, más bien se buscaba que los beneficiarios desarrollaran actividades asociadas a uproyectos de utilidad social y comunitaria" con un impacto en el mejoramiento de la "calidad de vida de la localidad". Este tipo de contraprestación siguió siendo una característica de los programas en el periodo que fue del 2003 al 2015. No obstante, este se destacó por la generación un conjunto de organismos declarados como promotores de "la economía social y solidaria", la creación de programas asociados a la incubación de cooperativas y a la existencia de instituciones asociadas a brindar protección social a los trabajadores "autogestionados" (Hopp, 2017).

\subsection{RECONOCER LOS LÍMITES DEL MERCADO LABORAL SIN TRANSFORMARLO: \\ COOPERATIVISMO Y ECONOMÍA POPULAR}

Después del 2003, se le otorgó al Estado un rol activo en la generación de puestos de trabajo y mejoramiento de las condiciones laborales (Grassi, 2012; Messina, 2017). Los discursos y los mecanismos orientados a dar respuesta a los trabajadores autogestionados fue producto del reconocimiento de la incapacidad "estructural del capitalismo de generar empleos para la totalidad de la fuerza de trabajo que se ofrece en el mercado" (Danani y Hintze, 2014; 312). Si en los noventa las posturas más liberales condenaban el sistema de 
protección como ineficiente social e de inutilidad productiva, con la emergencia de gobiernos más progresistas en la región, se comenzó a proponer un sistema amplio, incluso universalizante (Becher, 2017).

En este contexto las instituciones estatales asociadas a lo que tradicionalmente se llamaba economía social y solidaria (ESS) tendieron a crecer a nivel nacional y provincial. Inclusive en el 2008 se creó la Subsecretaría de Comercialización de la Economía Social, dependiente del MDS (Decreto 2194/08). En ese periodo se fundaron tantos organismos destinados a la promoción declarada de la ESS como los que se fueron generando durante más de 30 años en la que se considera economía social tradicional ( es decir, a la típica asociada al mutualismo y cooperativismo propia del siglo XX). Las principales tareas de las unidades organizativas inscriptas en los organismos públicos se orientaron a múltiples tareas: promoción, capacitación, formación, apoyo técnico, asistencia económica y financiera y transferencia de recursos, evaluación de proyectos productivos, articulación entre familias o grupos asociativos y planes sociales nacionales. En el discurso se detecta la referencia a población vulnerable y empresas auto gestionadas, cooperativas y mutuales, pequeñas comunidades rurales y un poco menos a destinatarios de los programas sociales (Costa, et al., 2011). En el año 1996 se creó el Instituto Nacional de Asociativismo y

Economía Social (INAES), dependiente del Ministerio de Desarrollo Social, para regular al cooperativismo y mutualidad en Argentina. Pero después del 2004 esta institución se robusteció en gran parte por la cantidad de cooperativas que tuvieron una expansión inédita (Deux Marzi y Hintze, 2014)

A través de la Ley 25.865 se implementó un nuevo sujeto económico "Efector de Desarrollo Local y Economía Social» y con él, un registro nacional. Este quedaba bajo la órbita del Ministerio de Desarrollo Social (MDS) con la intención de "facilitar la inclusión en la economía formal». La iniciativa permitía que los "emprendedores" facturaran por sus servicios y productos, alcanzando nuevos clientes, incorporándose al sistema previsional, recibiendo servicio de obra social a través de ser proveedores del Estado (nótese la ausencia de la referencia de trabajadores). ${ }^{5}$

En particular, el discurso cooperativista y de los trabajadores de la economía social y solidaria, creció durante los noventa al calor de las organizaciones de la sociedad civil y las empresas recuperadas. No obstante, después del 2003 el boom del cooperativismo fue impulsado desde el Estado (Hudson, 2017). 


\section{Grafico 1.}

Distribución de cooperativas bajo la órbita de programas sociales (2014)

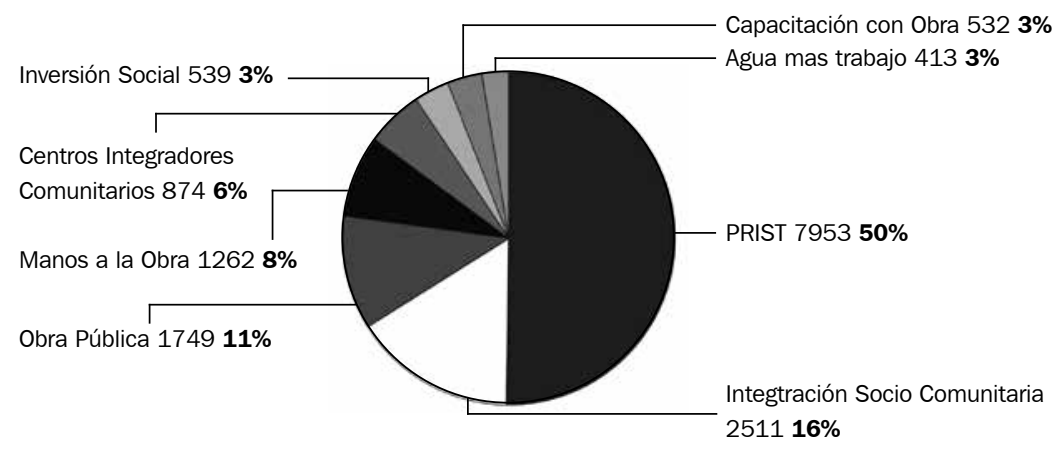

Fuente: Elaboración propia en función de datos Bustos y Molina (2016)

Para el año 2016, las cooperativas impulsadas por los programas superaban las 20.000. Para proteger a estos trabajadores se había creado el Monotributo Social que facilitaba (aun existente en la actualidad) la emisión de facturas, el acceso a la seguridad social, jubilación y obra social. Además, el Programa Nacional de Microcrédito para la Economía Social y Solidaria tenía como destinatarios a personas que no contaban con garantías patrimoniales o no reunían las condiciones para acceder a créditos bancarios tradicionales. En el año 2014 se registraron 440.000 personas afectadas por ese programa. Además se impulsaron leyes específicas y más programas específicos para el sector (Ley de Quiebras y leyes de expropiación, la Ley de Marca Colectiva, el Programa Federal de Emergencia Habitacional del Ministerio de Planificación y el Programa de Trabajo Autogestionado del Ministerio de Trabajo, Empleo y Seguridad Social). Se destacan los Proyectos Socio productivos "Manos a la Obra" (2004), el Programa Ingreso Social con Trabajo (2009) y el Ellas Hacen (2013) por su cobertura, la generación de cooperativas y el presupuesto brindado ${ }^{6}$ (ver Cuadro 1) 


\section{Cuadro 1.}

Cobertura de personas y unidades productivas en los programas.

\begin{tabular}{|c|c|c|c|c|c|c|}
\hline & 2011 & 2012 & 2013 & 2014 & 2015 & 2016 \\
\hline \multicolumn{7}{|c|}{ 1) Ingreso Social con Trabajo: Terminalidad Educativa y Capacitación en Oficio } \\
\hline (\# personas) & 35.559 & 54.303 & 127.500 & 177.330 & 245.536 & \\
\hline \multicolumn{7}{|c|}{ 1) Ingreso Social con Trabajo: Ingresos de Inclusión } \\
\hline & 92.691 & $38.508,5$ & 492.046 & 257.534 & 286.072 & 419.887 \\
\hline \multicolumn{7}{|l|}{ 2) Ellas hacen } \\
\hline (\# personas) & & & & 29.943 & 36.592 & \\
\hline \multicolumn{7}{|c|}{ 3) Proyectos Socio productivos "Manos a la Obra" } \\
\hline (\#unidades productivas) & 1.245 & 1.911 & 1.704 & 2.318 & 1.427 & 2.385 \\
\hline \multicolumn{7}{|c|}{ 4) Programa de Empleo Comunitario } \\
\hline (\# personas) & 295.133 & 65.614 & & & & \\
\hline
\end{tabular}

Fuente: elaboración propia en base a CEPAL

Si bien no desaparecieron, el peso de las cooperativas agrarias, de servicios públicos y de consumo vinculadas al cooperativismo y mutualismo tradicional se debilitaron en relación al total (ver Cuadro 2).

\section{Cuadro 2.}

Cooperativas registradas según tipo de actividad

\begin{tabular}{lrr}
\hline & $\mathbf{2 0 0 1}$ & $\mathbf{2 0 1 4}$ \\
\hline Agropecuarias & 2236 & 1297 \\
Consumo & 252 & 195 \\
Crédito & 341 & 290 \\
Provisión & 1544 & 1582 \\
Seguros & 51 & 19 \\
Servicios públicos & 1889 & 1167 \\
Trabajo & 6686 & 22516 \\
Vivienda y construcción & 3060 & 1789 \\
Total & 16059 & 28855 \\
\hline
\end{tabular}

Fuente: Bustos y Molina en base a INAES. 
El diseño de estos programas anclaba a estas cooperativas al brindar servicios al Estado y ser dependientes de los Ministerios, en particular del de Desarrollo Social, además de que las organizaciones tenían un gran protagonismo por devenir en parte de los entes ejecutores. En la letra de estos programas se hacía referencia al horizonte de la capacitación y terminación de estudios primarios, secundarios y de oficios (asociados a la construcción, formación integral sobre derechos, cooperativismo y economía social, perspectiva de género y ciudadanía urbana). La generación de este "capital social" a partir de esta participación en las cooperativas actuaba de promesa de inserción futura en un empleo decente. En el caso del PRIST se expresaba la intención de "creación de empleo digno desde la economía social y solidaria" (como cita la resolución del Ministerio de Desarrollo Social de la Nación N3182/09). No obstante, el ingreso era de la mitad de un salario mínimo, la protección débil y la formación endeble (Arcidiácono y Bermúdez, 2017) ${ }^{7}$ Meses después se crearía la Asignación Universal por Hijo para la Protección Social (AUH) que, a diferencia del anterior, este fue presentado como un programa de transferencia condicionada y en materia de cobertura fue el más más importante en la historia reciente del país (Cechini y Madariaga, 2011). Este tuvo la singularidad de ser un análogo a la asignación familiar pero para aquellos trabajadores asalariados informales y no asalariados, entre los que se encontraban los trabajadores del PRIST. Desde este punto de vista, acompañaba a estas familias como complemento monetario del primero. Al Programa Ingreso Social con Trabajo (PRIST), línea Argentina Trabaja, podían acceder personas desocupadas que no percibieran ningún tipo de subsidio social (excepto como se dijo la AUH). ${ }^{8}$ Estos debían adherirse al mono tributo social y recibían un ingreso mensual por tareas de hasta 40 horas semanales. Hasta que cambió la reglamentación en el 2016, los "efectores" debían formar una cooperativa que tenía que ponerse a disposición de un Ente Ejecutor. De estos participaban los municipios, las provincias y el Instituto Nacional de Asociativismo y Economía Social —INAES — las federaciones de cooperativas, muchas de ellas impulsadas por las organizaciones sociales, y mutuales. ${ }^{9}$ Para el año 2017, 130.000 cooperativas dependían del AT y 50.000 de la línea del Ellas Hacen (Arcidiácono, et. Al., 2013; Arcidiácono, y Bermúdez, 2015; Danani y Hintze, 2011; Hopp, 2016).

En términos generales estos programas estuvieron envueltos en una serie de discusiones académicas y políticas. Un cuestionamiento general fue que mantenían cierta continuidad con las políticas asistenciales previas, sin transformar de fondo las condiciones de la población cubierta (Antia, 2017). La institucionalidad no lograba generar amplias condiciones de protección social 
y regulación del trabajo asociativo. Además, no lograba generar relaciones de intercambio con la economía nacional de forma tal que rompiera con las desigualdades entre los trabajadores formales, los cooperativistas y autogestionados. En esas condiciones era difícil que se lograran formar asociaciones autónomas o empresas de propiedad conjunta democráticamente controlada. (Danani y Hintze, 2014; Hopp, 2017; Arcidiácono y Bermúdez, 2017). Otra crítica era que desincentivaban el ingreso al mercado de trabajo. Eran comunes los discursos asociados a que la desocupación, subocupación y la informalidad se mantenían porque no había incentivos de ingreso al mercado laboral debido a la existencia de las personas en los programas sociales. Recuérdese que incluso en la letra del programa Trabajar la justificación para otorgar una mensualidad baja, era provocar los incentivos necesarios para ingresar al mercado de trabajo en un contexto de destrucción del empleo. No obstante, un estudio realizado por Groisman (2016), con datos para el año 2013, demuestra que Ios hombres con AUH, por ejemplo, tenían mayores probabilidades de ingresar a la actividad económica que de devenir en población inactiva. Asimismo el salario mínimo (SMVM) también fue una institución laboral muy importante en proteger a los sectores más vulnerables de los trabajadores (Trujillo y Retamozo, 2017). Debido a las características segmentadas de los mercados de trabajo, fue una forma en que los trabajadores de los deciles más bajos se vieran favorecidos en materia de ingresos. Tampoco el SMVM impactó de manera negativa en los niveles formalidad, rompiendo con la hipótesis de que esta política colabora con el engrosamiento del mercado informal. No obstante, es necesario aclarar que esta política impactó de manera más positiva entre los trabajadores formales (Arcidiácono, 2015).

Si bien es de destacar que estas políticas fueron positivas en mejorar la distribución del ingreso y en mejorar la calidad de vida de los trabajadores más pobres, la persistencia del trabajo de subsistencia continuó siendo muy significativa. En el año 2014, sumando a los trabajadores por cuenta propia de oficios y subsistencia, más los de los programas sociales (2.249.800), las personas ocupadas en el servicio doméstico (1.349.000), las que realizan tareas familiares sin remuneración (133.000) y asalariados no registrados que se emplean en unidades informales de escaso valor agregado (489.090), el número ascendía a 4,3 millones (Arango et al, 2017).

Hay que subrayar el hecho de que el engrosamiento de la EP en este periodo se debió tanto a las políticas de transferencias de ingresos que aumentaron durante todo el periodo 2003-2015 como a otro conjunto con políticas laborales activas y a un contexto de mejoramiento de los salarios en el sector 
privado. Esto otorgó un derrame que favoreció el crecimiento del consumo y la financiación en y de la economía popular (CISBA, 2015; Roig, 2015). Si bien no existió una alta movilidad entre segmentos laborales, si existió una difusión económica a través de la contratación producto de changas, servicio doméstico, formación de mercados populares, composición de las familias con trabajadores formales, informales y trabajadores de programas sociales, etc. (Arango et al.2017). Esto generó oportunidades de formación o consolidación de unidades productivas de la economía popular, asociadas a las empresas recuperadas, agricultura familiar, trabajadores del espacio público (artesanos, feriantes, cuidacoches, tarjeteros, etc.), cartoneros y recicladores urbanos, trabajadores domésticos, (Narodowski, 2013).

Así, mientras se observa el peso legitimador puesto en el empleo y en las instituciones asociadas a él, en ningún caso se enuncia a este circuito de la economía como de los trabajadores, tarea que irían reivindicando las organizaciones sociales.

\subsection{DE BENEFICIARIOS A TRABAJADORES DESOCUPADOS}

«Nosotros luchamos por trabajo digno... Nosotros no somos vagos, somos trabajadores... Hacemos el piquete para protestar por los planes sociales pero eso no nos hace salir de ser pobres, queremos que cambien las cosas para no estar más sin trabajo ${ }^{10}$ "Para generar trabajo es necesario cambiar las formas de reproducción del capitalismo actual»" "Mirá, todos tenemos diferentes estrategias, diferentes posturas políticas, pero la base es la misma, los desocupados, los pobres, los excluidos, la gente que se quedó afuera (...) y eso es culpa de todos esos malditos" ${ }^{12}$

Las políticas públicas generan un marco de acción para que las organizaciones pudieran actuar, no solo aprovechándolo sino incluso forzando a su trasformación. Así existió un desplazamiento creativo donde interactuaron las organizaciones sociales y las políticas públicas donde las formas de nominación y organización cambiaron: del trabajador desocupado al trabajador de la economía popular, de la organización social al sindicato y del reclamo de subsidio a la propuesta de política pública.

En este sentido, la emergencia de los programas de empleo como el Trabajar y el PJyJH fue interpretada como una herramienta para controlar el conflicto social (Svampa y Pereyra, 2003, Delamata, 2004), como una forma de dismi- 
nución de la indigencia (Godio, 2003), como una oportunidad para la caza de los recursos, desafiando las formas clientelares de los gobiernos municipales y los "punteros" del partido justicialista (Merklen, 2005) o como acciones que consolidaron «la matriz asistencial del modelo neoliberal» (Svampa, 2005: 254).

Pero también puede existir otra forma de analizar este proceso. Las organizaciones sociales en Argentina fueron partes centrales de la conformación de una nueva caracterización en torno a los trabajadores («de la economía popular") y sus diferentes tramitaciones como problema social.

Desde la aparición de las organizaciones de "trabajadores desocupados" hasta la emergencia de los "trabajadores de la economía popular" durante los últimos años, las demandas cambiaron y la relación con los gobiernos fueron diferentes, pero la cuestión del "trabajo" como eje estructurador de las acciones desde la sociedad civil fue la constante. En Argentina, el trabajo no es solo una relación social que permite el acceso a un ingreso para la compra de bienes y subsistencia. Alrededor del mismo se condensa una serie de significados asociados a las luchas sociales históricas que pasan por la conformación del "movimiento obrero peronista" de mitad de siglo XX pero se anclan en la creación del Estado Nación a fines del siglo XIX y principios del XX. Ser trabajador estaba asociado en gran parte del imaginario social a un conjunto de relaciones como ser poseedor de derechos, acceder a la justicia social y a una vida digna y participar de la vida política del país (Muñoz, 2017; Retamozo, 2006). Estos sentidos se sedimentaron y fueron trasmitidos no solo por los trabajadores como individuos o por el Estado a través del régimen de bienestar sino también gracias a las organizaciones sindicales. En este contexto se deben comprender las luchas por el reconocimiento de las personas que viven de la «economía popular" como trabajadores con plenos derechos.

Lo más importante a destacar son los desplazamientos producidos en varios planos: en los sentidos al respecto de la auto/nominación, en los usos de los recursos públicos y en la búsqueda de reconocimiento frente al Estado y frente a la sociedad.

Ya se dijo que el tratamiento de la población objetivo de los programas cambio de "beneficiarios» con un perfil asistencialista, no productivista, a otro más centrado a la figura del "trabajo". Si bien en los programas Trabajar (I, II y III) nombraba a los "trabajadores desocupados" y se prestaba atención al proyecto sociolaboral, tenían un impacto limitado en materia de pobreza y se esperaba el ingreso de los beneficiarios en un empleo formal. Con el PJyJH se acentúa este perfil de combate a la "vulnerabilidad social». A pesar de que el Ministerio de Trabajo, Empleo y Seguridad Social estaba a cargo de la instrumentación, la 
autoridad de aplicación pasó a ser el Ministerio de Desarrollo y Medio Ambiente (Manzano, 2013). No obstante, la oportunidad de que las organizaciones fueran receptoras de los mismos, habilitó a las operaciones de re significación de dichos "subsidios". La creación del "Trabajar» impactó de lleno en su dinámica puesto que le proveía de recursos a las mismas. La masificación del PJyJH en el año 2002 les dio un impulso inusitado en tanto que tuvo como consecuencia la expansión del volumen de sus adherentes (Delamata, 2005). Para el año 2003, más de 200.000 ingresos proveídos por el programa estaban en manos de las organizaciones. Además, cerca de 1800 consejos consultivos locales se insertaron en los gobiernos municipales con el objeto de gestionar el PJyJH (Cechini y Madariaga, 2011). A pesar de que las mismas comenzaron a tener mucha presencia en la arena local, la estrategia fue actuar también sobre la nacional estatal, "re articulando la obtención del subsidio a la adquisición activa de un derecho, asociado a una categoría genérica: la de trabajadores sin trabajo" (Delamata, 2005; 369). En este sentido, las mismas impulsaban que las transferencias fueran contabilizadas como salarios a cambio de una contraprestación laboral en micro emprendimientos de subsistencia (huertas, panaderías, merenderos, etc.). En otros se consideraba como parte de una estrategia mayor de construcción de redes de una economía social alternativa (Svampa, 2005; Massetti, 2004).

Si bien se registran protestas desde mediados de los noventa, durante la crisis del 2001 y ya comenzado el 2002, el movimiento piquetero había alcanzado presencia en la escena pública nacional tras la reivindicación de "trabajo digno" (Muñoz, 2010). A pesar de la fragmentación política de las organizaciones, las diferentes tradiciones ideológicas y la heterogeneidad de sus bases, este había logrado tener cierta unidad simbólica tras aquella consigna y en enemistad al "neoliberalismo". Las organizaciones que conformaban sus bases se autodenominaban en su mayoría como de "trabajadores desocupados". Agregado a ello, desde las nacional populares a las clasistas o autonomistas, desde las más sindicales a las que tenían una estrategia electoral partidaria, todas aquellas demandaban específicamente "planes sociales" y subsidios de alimentos (Svampa y Pereyra, 2003; Muñoz, 2004). Para el 2001, se había logrado cierto acercamiento entre estas organizaciones y el movimiento de "fábricas recuperadas", las asambleas vecinales, la Central de Trabajadores Argentinos y partidos políticos, con quienes formaron alianzas de diversa envergadura (Mariotti et al, 2007). Así, el movimiento piquetero se volvió eje de la exigencia de trabajo como falta de derecho en tensión con la demanda de gestión de las políticas sociales (Merklen, 2005). Es importante aclarar que si bien la demanda cor- 
porativa o sectorial estaba orientada a la obtención de dichos ingresos, no se consideraba "trabajo" a la contraprestación ofrecida por esos programas. Como se verá a continuación, la continuidad de este tipo de programas en un contexto de ampliación del empleo asalariado y de discursos trabajo y estado céntricos, transformó las reivindicaciones sociales y sus formas de argumentación pública.

\subsection{DE TRABAJADORES DESOCUPADOS A TRABAJADORES DE LA ECONOMÍA POPULAR}

"En este contexto de ajuste y deuda, de buscar ayuda en los que siempre nos condenaron a grandes crisis, el sector de la economía popular sigue organizándose y apostando a la unidad para seguir peleando por sus derechos como trabajadores y trabajadoras. Por esto saldremos a las calles desde los barrios de todo el territorio nacional e iremos al Congreso para avanzar en la lucha por Tierra, Techo y Trabajo representada en un conjunto de leyes..113

Después del año 2003, el contexto para las organizaciones de trabajadores desocupados se transformó. A las organizaciones que no estaban de acuerdo con el gobierno no se les concederían "planes" pero tampoco serían reprimidas. (Svampa, 2005). Además, algunas de ellas fueron integradas a puestos de decisión relativa en el Estado, en particular en el Ministerio de Desarrollo Social (Muñoz, 2010). ${ }^{14}$

Las protestas se fueron transformando. Si durante los noventa las organizaciones sindicales y las demandas por aumento de los salarios tendieron a debilitarse, después del 2003 se volvieron a fortalecer (Palomino, y Trajtemberg, 2006). La explicación de la emergencia de la conflictividad sindical no puede escindirse del fortalecimiento del empleo en el sector privado y de la reactivación de políticas como la negociación colectiva y la fijación tripartita del salario mínimo, vital y móvil (Novick, 2016). Esta dinámica fue virtuosa hasta el año 2008 donde los indicadores económicos se desaceleraron, tendiendo a estancarse luego del 2012 (Messina, 2017). En el marco del crecimiento de la dispersión de las realidades de los trabajadores (pobres, informales, cuentapropistas, vulnerables, cooperativistas...) y debilitadas los puntos de referencias de los piqueteros o trabajadores desocupados, las organizaciones crearon un nombre que podía favorecer una nueva identificación que no existe en las definiciones normales: el trabajador de la economía popular (TEP).

Aproximadamente a partir de 2008, el Movimiento Evita, el Movimiento de Trabajadores Excluidos y otras organizaciones sociales comenzaron a generar un 
diagnóstico y una propuesta. El diagnóstico era que un tercio de la población no incluida en el mercado laboral formal persistía, a pesar de las transformaciones realizadas (Grabois y Pérsico, 2014). Además, estos no eran "empleables" o "no empleables", menos aún, "ni vagos ni víctimas", «ni subsidiarios de la distribución del ingreso". Esta era una parte de la población excluida por el "neoliberalismo" y que era sujetos de derechos que faltaban ser incluidos o en el peor de los casos, el capitalismo no los incluiría nunca.

El gobierno había puesto al trabajo como eje de la integración social y al Estado como "universal» a perseguir bajo la idea de «inclusión social» (Messina, 2017; Muñoz 2017). Pero como se analizó, no se universalizaron ni las políticas sociales ni se propagó el empleo formal entre los sectores más empobrecidos. El objetivo era evitar que se desincentivara la búsqueda de empleo producto del acceso a la provisión de bienes y servicios vía ingresos públicos. Se seguían sosteniendo discursos asociados al capital social, es decir, a la ampliación de las capacidades humanas (terminación educativa, capacitaciones de oficio, etc.) para aumentar las oportunidades de empleo bajo un diagnóstico que se basaba en las capacidades de integración del mercado de trabajo en un futuro próximo.

Las organizaciones se apropiaban de esta trama significativa generada desde el gobierno para reivindicar que aquellos que habían tenido la capacidad de generar su propia forma de trabajo, incluso bajo el calor de las políticas públicas, debían ser reconocidos por el Estado como trabajadores con derecho. Las realidades eran heterogéneas: desde las formas cooperativas e ingresos provenientes del Estado, pasando por las empresas recuperadas hasta todo aquel trabajador que no tenía ni "ni salario» «ni patrón evidente».

Así las demandas generales (no así las particulares) se transformaron en un número considerable de organizaciones. El movimiento piquetero (incluso con las contradicciones ideológicas internas clasistas, nacional populares $u$ horizontalistas) logró instalar en la escena nacional la reivindicación de que el Estado debía dar respuesta a que la economía ofreciera trabajo digno (Svampa y Pereyra, 2003). Después de varios años de mejoramiento de las condiciones de bienestar, numerosas organizaciones sociales comenzaron a desplazar el futuro para el presente: se buscaba que los reconocieran como trabajadores en la actividad que ejercían, no como objeto de relaciones laborales en el futuro. Esto implicó cuestionar el estatuto del trabajo, de las políticas públicas y del Estado.

La propuesta se concretó en el año 2011. Esta era organizar bajo una Confederación a los trabajadores de la economía popular. La retórica de la CTEP creó (como el discurso gubernamental) una frontera política con el neoliberalismo, en tanto aquel, había dividido a los "trabajadores entre aquellos que 
contaban con trabajo formal y estaban representados por la CGT y trabajadores que contaban con empleos informales y trabajos precarios " ${ }^{15}$ Había entonces que hacer un proceso similar al que había hecho el "sindicalismo peronista" históricamente: «luchar por los derechos». ${ }^{16}$

En ese camino, el 20 de diciembre de 2011 se lanzó la Confederación de Trabajadores de la Economía Popular como entidad gremial (no reconocida por el Estado) en la que confluyeron el Movimiento Evita, el Movimiento Nacional de Empresas Recuperadas (MNFR), el Movimiento de Trabajadores Excluidos (MTE), La Alameda y la Federación de Trabajadores de Cooperativas de Infraestructura Social (FeTraCol), entre las organizaciones más destacadas. En el año 2015, le es otorgada la personería social (Grabois, 2017). La CTEP declaró en las bases de su fundación la intención de ser parte del movimiento obrero organizado y su expresión organizada la CGT. Recién en el año 2016 la CGT crearía en sus regionales las "Secretarias de Economía Popular", produciendo un camino hacia la categorización de estos trabajadores en tanto tales desde los sindicatos "formales".

Las demandas de la CTEP fueron múltiples y heterogéneas pero se pueden organizar en dos grandes grupos; las de carácter social y las de carácter político. Las primeras mantienen las estructuras de las políticas públicas. Dicho de otra manera, exigen el aumento de las personas y los montos en los programas sociales, subsidios, etc. (Muñoz y Villar, 2017). Las segundas hacen referencia a las que no pueden ser contenidas por los esquemas institucionales en los cuales se desenvuelven, por ejemplo, como es el caso que se está analizando, el ser reconocidos como trabajadores. En este punto es donde se puede observar un quiebre con las demandas del movimiento piquetero. Estas apuntaban al vacío estructural del "sistema" (de relaciones de producción, de trabajo, de inclusión social). El gobierno tenía un discurso acerca del "trabajo" como forma de inclusión social. La forma paradigmática (o el particular inclusivo) que este elegía era el modelo tradicional de "empleo decente" (asalariado y sobre todo producido en el sector privado) de acuerdo con el paradigma neo desarrollista en el cuál se inscribía el discurso gubernamental (Messina, 2017). Frente a esto, la CTEP demandaba al Estado ser reconocido como organización sindical y a sus adherentes como trabajadores (de la economía popular). Existía un paquete de reivindicaciones que excedía la protección social a estos sectores como por ejemplo la creación del Ministerio de Economía Popular y de un salario social financiado por el Estado que les permita alcanzar el SMVM. Además del pedido de una obra social, de licencia por maternidad y vacaciones, se reclamaba la convocatoria a paritarias "populares" que incluyera a cuentapropistas 
comunitarios e informales en sus distintas ramas de actividad, la promulgación de un convenio colectivo de trabajo para los trabajadores auto gestionados (como los de las cooperativas AT) y la regulación de sus condiciones de trabajo. En otras palabras, se pedía la igualación de derechos en relación con los trabajadores formales. ${ }^{17}$

\section{4 debilitaMiento del MOdELO ESTAdO Y TRABAJO CÉNTRICO $Y$ «RECONOCIMIENTO" DE LOS TRABAJADORES DE LA ECONOMÍA POPULAR}

En las elecciones presidenciales del año 2015, Mauricio Macri ganó en segunda vuelta a la fórmula de Scioli - Zannini. Las políticas implementadas por este gobierno dieron un giro regresivo en materia de distribución del ingreso, empleo y trabajo. Hubo despidos y nuevas contrataciones en el sector público, la moneda nacional se devaluó, la inflación no pudo contenerse sobre todo en la canasta de alimentos, se le retiraron los impuestos al sector agroexportador y minero y aumentó la importación desfavoreciendo a los productores locales (Varesi, 2016: CESO, 2017; MTEySS, 2018). En ese contexto adverso para los trabajadores en general y para los trabajadores de la economía popular en particular, el gasto social se mantuvo constante y el asistencial aumentó en relación al periodo anterior (Seiffer y Rivas Castro, 2017).

Hay que aclarar que la desocupación no se volvió un dato significativo como en los noventa. Más bien el mercado de trabajo se caracteriza, en este periodo, por el aumento de la precariedad generada por la persistencia de la informalidad, la creación de trabajo en puestos de bajos ingresos sumada al aumento de los monotributistas, en particular, los sociales (ODEP; 2018). Además, según los datos que se disponen a partir de los entrevistados, de las fuentes del Ministerio de Desarrollo Social y del Ministerio de Trabajo, Empleo y Seguridad Social, el gobierno aumentó los ingresos a los programas como el Argentina Trabaja y la AUH (ver Cuadro 1), pero disminuyó la cobertura de las políticas de empleo del MTEySS durante el 2016. ${ }^{18}$

El 14 de diciembre de 2016, el congreso nacional votó por unanimidad la Ley de Emergencia Social. La ley tiene por objeto "promover y defender los derechos de los y trabajadoras que se desempeñan en la economía popular, en todo el territorio nacional, con miras a garantizarles alimentación adecuada, vivienda digna, educación, vestuario, cobertura médica, transporte y esparcimiento, vacaciones y protección previsional. El fundamento se legitimó en las garantías otorgadas al "trabajo en sus diversas formas", presente en el artículo 
14 bis y en el mandato de procurar "el progreso económico con justicia social" establecido en el artículo 75 (inciso 19), ambos de la Constitución Nacional.

Es la primera vez que una ley es propuesta por un conjunto amplio de organizaciones y sancionada respetando gran parte de la misma. Esta instruyó la creación de un Registro Nacional de la Economía Popular (RENATREP) donde serían inscritos los trabajadores de la economía popular, la formación de un Consejo de la Economía Popular y Salario Social Complementario (CEPSSC) conformado por tres miembros del gobierno nacional y tres representantes de las organizaciones sociales y la creación del Salario Social Complementario (SSC). Además, impulsa la conversión de los programas sociales al SSC.

La concesión de los beneficios a los trabajadores de la economía popular como el SSC plantea al menos dos escenarios. Por un lado, podría contribuir a la cristalización de un sector de los trabajadores en calidad de pobres o precarios. Por el otro, el reconocimiento como "trabajadores" podría abrir el juego a futuras demandas de ampliación derechos laborales. Existen argumentos políticos y académicos en favor de una y otra posición.

Seiffer y Rivas Castro (2017) sostienen que "las políticas del macrismo refuerzan la fragmentación y la tendencia a la asistencialización de la política social, pues profundizan la consolidación de sectores cada vez más amplios de la clase obrera en sobrantes para el capital» (p. 107). Hopp (2017) señala que esta Ley marca un giro en la estrategia de intervención social del Estado sobre las situaciones de vulnerabilidad social, creando una nueva transferencia monetaria que se concibe como un complemento del trabajo en la economía popular, pero con una orientación hacia la formación laboral y la eliminación de la cooperativa. De esta manera «borra la asociatividad y la autogestión del trabajo" y "reenvían la intervención estatal a la esfera de la asistencia a la pobreza y reactualizan las tensiones entre la concepción del trabajo como un medio de integración social y su uso como un recurso de la asistencia" (p. 36). Finalmente, considerando que la suma que recibe un trabajador de la economía popular en concepto de SSC es de la mitad de un SMVM, es evidente que la continuidad en la precariedad es un hecho. Y, la urgencia en la que viven estos colectivos, los podría haría limitar a demandar paupérrimos pero necesarios beneficios en lo inmediato sin tener una estrategia a largo plazo. ${ }^{19}$

No obstante, como se señalará a continuación, estas limitaciones son reales pero no describen el fenómeno de manera acabada. Las organizaciones reivindican las posibilidades que abre la ley. «Esta ley es producto de la lucha de más de cinco años. Una de las conquistas es el salario social complementario que viene a reconocer nuestro trabajo cotidiano como trabajadores de la eco- 
nomía popular y a solventar algunas necesidades económicas en un contexto muy complicado (...) Somos un sector históricamente marginado pero desde el 2015 nuestra situación es cada vez peor» (Entrevista a referente de la CTEP) En este sentido, las organizaciones observan que aunque la situación del país empeoro después del 2015. La ley, en conjunto con otros procesos, abre la posibilidad de profundizar la lucha por el reconocimiento.

\subsection{POLÍTICA PÚBLICA Y CONFLICTIVIDAD SOCIAL}

La ley no fue una iniciativa del gobierno, como si lo fueron durante periodos previos, sino que resulta de un proceso de alta conflictividad, articulación entre las organizaciones y de una negociación posterior. El gobierno de Cambiemos puede ser caracterizado como de centro derecha, con una concepción de modernización gerencial política del Estado y de desregulación controlada. Llego al poder con minoría parlamentaria y sin control de la mayor parte de los gobiernos provinciales por lo que estuvo obligado a negociar con la oposición las medidas emprendidas (Vommaro y Gene, 2017). Esto fue aprovechado por los diferentes colectivos.

En un contexto de múltiples protestas con demandas asociadas al trabajo que se dieron en todo el país, el 18 de noviembre de 2016, la Confederación de Trabajadores de la Economía Popular (CTEP), Barrios de Pie (BdP) y la Corriente Clasista y Combativa (CCC) marcharon reclamando la emergencia social y laboral. Ya sea por cálculo táctico (a razón de necesitar ese recurso para la movilización) o por coincidencia en torno a las razones de la ley, la CGT y las dos CTA estuvieron desde los inicios en la organización de esa marcha y respaldó las demandas de este colectivo en general. Previamente, la multitudinaria movilización del 7 de agosto del 2016 por el día de San Cayetano, patrono católico del "pan y del trabajo", había consolidado la alianza entre las organizaciones populares (CTEP, CCC y BdP). La tumultuosa jornada (se calculó que hubo más de 200.000 personas en un recorrido que duró más de 4 horas) fue la primera de muchas más, pero tuvo la característica de ser un puntapié inicial para instalar el nombre de "los trabajadores de la economía popular" en la escena nacional e iniciar un camino de articulación con otras asociaciones. ${ }^{20}$ Sindicatos de las diferentes centrales, confederaciones y partidos políticos estuvieron presentes en dicha acción y en las siguientes.

Las organizaciones nombradas tienen diferentes orígenes temporales e ideológicos. La CCC (1994) y BdP (2001) pueden remontarse al período de lucha del "movimiento piquetero" en los noventa. La CTEP como se dijo, nació en el 2011. La CCC es una agrupación político sindical del Partido Comunista 
Revolucionario y como tal participa de todos los sindicatos, federaciones y organizaciones laborales. Si bien en su crecimiento tuvieron mucho peso las luchas de los trabajadores desocupados (y uno de sus principales referentes proviene de allí) también representa a los trabajadores formales, a los jubilados y a pueblos originarios. BdP se creó desde la intención de organizar a trabajadores desocupados y actualmente es parte del Movimiento Seamos Libre de orientación nacional - popular. Mientras que la CCC se mantuvo en la oposición frente a los todos los gobiernos (Menem, De la Rua, Duhalde, Kirchner y Cristina Fernández de Kirchner), BdP paso de una posición de alianzas a un apoyo crítico con los gobiernos kirchneristas. La CTEP tuvo adentro de sus filas organizaciones aliadas y críticas a estos gobiernos (Muñoz y Villar, 2017)

No fue hasta el año 2016 que este conjunto variado de organizaciones comenzaron a bautizar por igual a los "trabajadores de la economía popular", dando unidad a una diversidad nominativa (trabajadores informales, en "negro", pobres, piqueteros, etc.). Este ejercicio incluyo el acercamiento a lo que se dio a llamar "la unidad en la acción", es decir, la coordinación de acciones colectivas tras demandas compartidas y un enemigo común. ${ }^{21}$ Las demandas eran la aprobación de la Ley de Emergencia Alimentaria, un salario básico universal de 15.000 pesos y el apoyo a demandas específicas de cada sector como el mantenimiento de los puestos de trabajo, aumento salarial, etc.

La frontera política construida frente al gobierno colaboró también con la unificación de la CGT en un triunvirato (agosto del 2016), la puesta en común de estas organizaciones nacionales en un "triunvirato de los trabajadores de la economía popular" ("triunvirato piquetero" o "Cayetano" como lo llaman los medios de comunicación) y las acciones de protesta compartidas entre las dos CTAs. La Central de Trabajadores de la Argentina (CTA) se formó en el año 1992 frente a las políticas pro liberalización de los mercados y anti laborales del gobierno de Menem (1989-1995; 1995-1999). Durante esos años se opuso a las prácticas de la CGT y al modelo sindical argentino en materia de monopolio de la representación sindical. Como estrategia, combinó recursos sindicales y movimentistas, incluyendo a los "trabajadores desocupados" no solo como base de apoyo sino como afiliados (Muñoz, 2010; Retamozo y Morris, 2015) En el año 2009 se dividió en dos a partir de las relaciones de apoyo y oposición a los gobiernos "kirchneristas". No obstante, con la asunción del gobierno de Macri, si bien no se unificaron, se acercaron en las acciones de protesta y apoyaron la presentación de la Ley de Emergencia Social.

En este contexto de acercamiento de las partes, el gobierno nacido después del 2015 eligió responder diferencialmente a las demandas en un intento de 
dividir la incipiente articulación. Otorgó el aval a la Ley de Emergencia Social, es decir, se comprometió a no vetarla como sí ocurrió con otras leyes y se le concedió a los gremios formales algunas demandas específicas como el bono de compensación por la pérdida del salario real a fines del 2016.

En materia de política social no redujo la cobertura pero cambió algunos mecanismos importantes. En primer lugar, suprimió la norma por la cual solo aquellos que estaban organizados alrededor de una cooperativa podían acceder al PRIST. Esto otorgo la posibilidad de que haya una fuga de las mismas hacia la individualización. No obstante, la mayoría de las altas y bajas de las mismas siguieron en manos de las negociaciones con las organizaciones sociales.

\subsection{SUBSIDIO 0 SALARIO}

La expectativa de las organizaciones (al momento de realizar este trabajo) es que el desplazamiento de los programas Argentina Trabaja, Ellas Hacen y Trabajo Autogestionado producto de la ampliación del SSC, no se convierta en la consolidación de una economía "de pobres para pobres" sino en las posibilidades abiertas por la ley. La estrategia no es defender una economía de subsistencia sino señalar la existencia de un conjunto de trabajadores que están asociados a otro tipo de relacional laboral para los cuales hay que desarrollar y consolidar sus derechos.

La ventaja de que éstos sean objeto del SSC tiene que ver con varias dimensiones sociales y políticas que destacan los entrevistados. En primer lugar, dejan de ser beneficiarios pasivos para convertirse en trabajadores activos con reconocimiento legítimo y legal. Esto no quiere decir que devengan automáticamente en sujetos de decisión o sujetos políticos con plenos derechos. Más bien señalan que la letra de la ley implica esta posibilidad. Dejarían de tener un estatuto de "beneficiarios" de programas sociales a ser reconocidos como trabajadores. En segundo lugar, al reconocérselos como trabajadores, no tendrían que ofrecer una contraprestación ya que su actividad es la que los autoriza a cobrar el salario. El Estado garantiza el derecho a un salario mínimo a trabajadores que ya se considera que tienen un trabajo en la economía popular. Así pues en la reglamentación (que sale varios meses después de sancionada la ley) se reconocen ramas y actividades que antes eran consideradas cómo trabajos informales, cuentapropistas o voluntariado social. En otras palabras, se abre la posibilidad de la re-nominación de estos trabajadores, como trabajadores (en un futuro formales independientemente de la actividad que realicen). Además, se compromete a un presupuesto específico para la implementación de la ley. Esto es muy importante puesto que anteriormente 
se habían generado instituciones reconociendo actividades específicas, como por ejemplo, la Subsecretaria de Agricultura Familiar que reconocía a estos sectores como trabajadores de la economía popular, pero sin la creación de un presupuesto para su actividad se volvía penoso el estímulo a la misma.

De nuevo, la creación de una ley no implica conquista y ejercicio pleno de los derechos, pero si una marca puesta en el orden social del paso de las demandas y su tratamiento. Las debilidades de la ley son evidentes. El SSC es la mitad del Salario Mínimo Vital y Móvil, lo que si bien les permite salir de la indigencia, no los elimina de la categoría de "trabajadores pobres" o "precarizados". Además, las formas de aplicación del SSC pueden derivar en la producción de otra figura del "asistido".

Por lo reciente de la medida es imposible avanzar sobre esto pero se puede reflexionar en torno a las potencialidades o futuros plausibles a ser desplegados por las organizaciones.

Se observa un impulso de ciertos sectores (CGT, CTAs, partidos políticos) a reconocer un nuevo colectivo de trabajadores, sacándolos de la lógica de "objetos de subsidios". Como estrategia política, esto es clave. El salario se constituye en una relación estructural y fuente de derechos sociales, políticos y económicos que solo han sido conquistados si existe un amplio reconocimiento social. Se reconoció la personería social a la CTEP, se pasó de otorgar «ingresos" a "salarios", se habilitó al Ministerio de Trabajo y Seguridad Social como contraparte en las negociaciones. En segundo lugar se generan mecanismos de institucionalización que, en contextos socio-económicos más favorables, podrían transformar la inserción de estos trabajadores en el resto de la economía. La ley sostiene que los programas nacionales se articularán alrededor del Consejo de la Economía Popular y Salario Social Complementario (CEPSSC) Esto podría permitir que las organizaciones construyan efectivamente identidades asociadas al trabajo como sede de derechos, algo que en Argentina no sería poco habitual como lo demuestra la historia reciente del siglo XX. Además, la ley sostiene que el salario debe asegurar vivienda digna, educación, vestuario, asistencia sanitaria, transporte, vacaciones, previsión, etc. (ley 20.744/art. 116).

Tomar como real, lo que se presenta como ideal podría ser una estrategia política transformadora. Para ello son importantes las tensiones a las que son sometidos los órdenes sociales. Las luchas de los trabajadores en Argentina situaron en el centro del orden social un antagonismo que puede sintetizarse como la puesta en escena de dos formas de comprender la sociedad; uno que se enlaza con el principio de producción y reproducción de la vida "digna” y otro que mercantiliza todas las relaciones sociales. En este sentido, la letra (¿muerta?) 
de esta ley pareciera atender. No obstante, se vota en el marco de un gobierno que atiende al segundo principio. Pero que esté en el marco de «la letra» habilita/ legitima ciertas acciones colectivas orientadas a perseguir este principio en un contexto donde la política económica y laboral se orientan hacia su opuesto.

Y las contradicciones de las instituciones pueden ser interesantes grietas donde hacen eje las organizaciones para crear programas públicas e instituciones. La Creación del Consejo de la Economía Popular y Salario Social Complementario (CEPSSC) en la órbita del Ministerio de Desarrollo Social de la Nación presenta tensiones en relación con este reconocimiento. Los que están autorizados a participar de las negociaciones que se producen en ese Consejo son por parte del Estado; el Ministerio de Trabajo y Seguridad Social, el Ministerio de Desarrollo Social, el Ministerio de Hacienda y Finanzas Públicas y por parte de las organizaciones sociales: tres inscriptas en el Registro de Organizaciones Sociales de la Economía Popular y Empresas Auto gestionadas. Es evidente que se los reconoce como trabajadores pero no tienen acceso a sus formas de organización (por ejemplo, la personería gremial). Se los sigue denominando "organizaciones sociales" y "empresas" y no sindicatos.

La personería sindical fue reclamada desde la CTEP (no así del resto de las organizaciones) al Estado y el 9 de diciembre del 2015 le es aceptada la personería social, a un día de cambio de gobierno. La formación de un registro de las organizaciones y sus trabajadores que se presenta en la Ley, permitiría fortalecer la organización sindical, permite generar argumentos en torno al peso económico y social del "sector" y generar estrategias de afiliación y colectivización de estos trabajadores. Ahora bien, una vez reglamentada la ley (facultad del ejecutivo nacional y realizado en abril de 2017) se abrió el registro del salario social complementario pero no se puso en marcha los mecanismos institucionales más amplios como este registro o el concejo.

El Consejo (CEPSSC) es un mecanismo interesante por su amplia facultad para generar políticas para el sector. No solamente, puede negociar los montos y números de beneficiarios del SSC sino también que puede diseñar y proponer los criterios y mecanismos de inscripción, admisión, clasificación y permanencia en el Registro Nacional de la Economía Popular, promover criterios unificados de elegibilidad y priorización para acceder al Salario Social Complementario, proponer mecanismos ágiles para la formalización, regularización y promoción de las unidades económicas de la economía popular, formular propuestas y recomendaciones al poder ejecutivo. Además, esto último está atado a las partidas presupuestarias, lo que le da al gobierno un amplio margen de decisión. Finalmente, las organizaciones ponen denuncian que el consejo no se 
ha implementado, más que a partir de reuniones informales que se dan entre las organizaciones y los representantes del Estado.

Esta supone una etapa diferente en materia de institucionalidad de economía popular: quedan inscriptas en la letra de la ley el reconocimiento a los trabajadores de la economía popular en tanto trabajadores como sujetos de derechos. Si las políticas asociadas al Trabajar I, II y III y el PRIST no habían logrado remover situaciones de estigmatización y estratificación social, esta tiene el potencial, en conjunto con otras variables, de poder hacerlo. Es sabido que las políticas sociales pueden reproducir este tipo de procesos que van en contra del bienestar que quiere producir, pero es materia de las interacciones entre las mismas y los diversos actores en juego la posibilidad de transformar las desiguales simbólicas y materiales. Pero no se trata de generar un proceso de difusión de las cooperativas al resto de la sociedad o de insertarlas en los mercados haciéndolas competitivas. Se trata de reconocer otro tipo de trabajo útil que no tiene valor en el mercado. Otra vez, el problema es que alcance tienen estas prerrogativas de la ley si no se ponen en marcha de manera plena. Estas innovaciones institucionales pueden quedar paralizadas producto de las relaciones de fuerza que ponen a las organizaciones en condiciones de debilidad frente a otros actores. La lucha de los trabajadores de la economía popular implica buscar reconocimientos sociales, de sí mismos como trabajadores, de otros trabajadores (como los formales), de la sociedad y del Estado. $Y$ esto supone luchar por los sentidos en torno a la sociedad, no solamente el "reconocimiento" de la "diferencia», sino por la integración de los mismos. De esta manera, los diseños de las políticas públicas deben tener en cuenta a los propios sujetos y las relaciones de poder que ellos entablan.

\section{CONCLUSIONES}

El crecimiento de las otras formas del trabajo, en particular, de aquellos que no tienen salario, ni derechos laborales, y viven en los límites de la pobreza, ha sido puesto en discusión política y académica las últimas décadas. No es de extrañar. En la Argentina el trabajo ha sido un eje estructurador de la política y los derechos, de la formación del Estado y de las políticas públicas. En este artículo se analizó cómo los colectivos asociados a demandas laborales (sea por demanda de empleo o por reconocimiento del trabajo que realizan) dejaron sus marcas en las políticas públicas durante los últimos 20 años. 
En la década de los noventa la emergencia de desocupación, la informalidad y la pobreza como problema público político estuvo asociado a la interacción entre las organizaciones y las políticas públicas. Desde la creación del primer programa Trabajar hasta la actualidad, las políticas sociales con contraprestación laboral o asociadas a la protección de los desempleados o informales, crecieron en cobertura de personas, de hogares y en presupuesto.

A pesar de esta tendencia general, se distinguieron periodos en función de las orientaciones generales de los gobiernos, el rendimiento de los mercados laborales y el comportamiento de las organizaciones. Después del 2001, en la etapa de formación del empleo en el sector privado, el acompañamiento de políticas activas de empleo y el reconocimiento del trabajo como forma de integración social, las cooperativas y las instituciones de ESS creció notoriamente tanto para proteger como para acompañar a los trabajadores del sector. Además fue el Estado el que impulsó una cantidad numerosa de cooperativas y se impulsaron medidas para mejorar las condiciones de igualdad entre trabajadores asalariados y no asalariados. No obstante, el entramado institucional no fue efectivo en combatir la formación del trabajo precario en todas sus vertientes (informalidad, trabajo de la economía popular, etc.).

Las organizaciones sociales construyeron potencias transformadoras a partir de otros ejes, más allá de que esta economía no pudo transitar a otra con "predominancia de la lógica de la reproducción ampliada de la vida de todos" (Coraggio, 2015: 11) o que se limitó «las posibilidades de reconocimiento social y cultural que favorecerían la generación de estas formas de trabajo al conjunto de la sociedad (Hopp, 2017: 52). La inscripción en el espacio público de las organizaciones, a través de la reivindicación general, se transformó; pasaron de denunciar la exclusión del mercado laboral a proponer la existencia de nuevas formas de trabajo y de nuevos derechos que debían estar asociados al mismo. Las demandas no eran puramente corporativas (en el sentido de buscar recursos para resolver la situación inmediata de un sector de la sociedad). No se trataba de organizaciones orientadas solamente a la resolución "asistencial» o a la reproducción de una "economía de pobres para pobres". Expresaban una serie de tensiones entre la necesidad de resolver las condiciones de subsistencia de la vida de los más pobres y la búsqueda de reconocimiento más amplio que implicaba una transformación mas general.

Con la creación de la CTEP como organización, la referencia de una nueva forma de trabajo tenía el potencial de desordenar ciertas escenas asociadas a las políticas públicas centradas en el trabajo. Los gestores de las mismas 
tenían una paradoja difícil de resolver. Si reconocían al sector como sujeto "de derechos", es decir, como trabajadores plenos, la especificidad de la vía elegida había fracasado Esta suponía la generación de empleo asalariado, la sustitución de importaciones, la producción nacional industrial, etc. Los trabajadores de la economía popular no tenían salario, no tenían patrón, no se guiaban por el criterio de productividad, ni tenían un valor reconocido en el mercado. Este ponía en tensión (aunque no necesariamente es antagonista a) la idea del empleo decente como una forma de relación social mediada de manera hegemónica por el mercado. No obstante, la salida al estancamiento del empleo en el año 2009 fue la creación del PRIST que consolido este tipo de trabajadores. Asi como los programas Trabajar y PJyJH, este fue re significado por las organizaciones sociales.

Después del 2015, en un contexto económico inflacionario, devaluatorio y con una institucionalidad precaria en protección de los trabajadores más vulnerables, en particular la política social parece devenir en mera asistencia frente al empobrecimiento. No obstante, en un contexto de debilidad parlamentaria y frente a las amenazas de las organizaciones de generar protestas masivas y problemas de gobernabilidad, durante el periodo festivo de fin de año, el 24 de noviembre de 2016, se firmó un acuerdo donde todos los bloques legislativos aprobaran por votación la Ley de emergencia Social. Las organizaciones se volvieron engranajes importantes de la política social pero también de la gobernabilidad.

El acceso al Salario Social Complementario resuelve condiciones mínimas de subsistencia al otorgarles medio salario mínimo como complemento a los ingresos de trabajadores "no formales". Esto ha sido una conquista no menor para aquellos que viven en condiciones de pobreza. Pero no se crearon coordinaciones sistemáticas entre Ministerios, políticas y organizaciones representantes de estos trabajadores, a pesar de que esté presente en la declaración de la Ley. Los grandes programas siguen quedando en la órbita de áreas sociales del gobierno y no en otras como producción, economía o trabajo. En este contexto adverso, las organizaciones sociales y los trabajadores de la economía popular se llevan la mayor tarea. El SSC es percibido en el marco de una unidad productiva, es decir, para completar los ingresos de aquellos trabajadores que generaron un bien o servicio para obtener ingresos. Esto implica que son los trabajadores y sus organizaciones los responsables de la existencia tanto de su trabajo como de la continuidad del complemento. Pero además, si el SSC es simplemente un subsidio del Estado, sin estar relacionado a una actividad laboral, perderá el potencial transformador que aquí 
se describió. Esto está asociado a las capacidades de construir subjetividades críticas, que les permitan a los trabajadores cuestionarse sus condiciones de existencia, organizarse, demandar y hacer propuestas. Allí están la tarea de las organizaciones, multiplicar la percepción de que los que lo reciben se vean así mismos como trabajadores con plenos derechos, para colectivizarse y luchar por los derechos que todavía se les escamotean. El reconocimiento efectivo de los derechos de los trabajadores de la economía popular es todavía una de las formas posibles de futuro, pero no una realidad efectiva. Dependerá, como en el caso de casi todos los derechos, de las luchas de los sujetos que las impulsan y de las relaciones de fuerza que se desarrollen.

La "economía popular" supone desdibujar a la economía como dividida entre pública y privada, a la población como empleable y no empleable. Apela a la institución de un Estado de Bienestar pero diferente al de la etapa de industrialización por sustitución de importaciones. Pone en cuestión la categoría del trabajo solo como aquel que tiene valor en un circuito del mercado. Todo esto requiere de diseños institucionales efectivos, pero también de la incorporación de derechos efectivos y consensos viables políticamente. A pesar de las debilidades, la sanción de la Ley de Emergencia Social pone en evidencia que existe un proceso de construcción de estrategias desde un conjunto de organizaciones que buscan soluciones políticas al principio de vida digna. En este sentido, una política pública efectiva es aquella que expresa un contrato social entre los gobiernos y la ciudadanía. No obstante, una política pública igualitaria es aquella que reconoce la dignidad de vida de la población, aun a costa de producir desequilibrios macroeconómicos y el «enojo» de los mercados. 


\section{NOTAS}

1 Las entrevistas en profundidad fueron realizadas en diferentes tramos de los años 2004, 2015 y 2017 , a referentes de movimientos de trabajadores desocupados y a la confederación de trabajadores de la economía popular (tanto del movimiento evita como del movimiento de trabajadores excluidos). Se utilizaron fuentes primarias (documentos, diarios y pasquines) producidos por la Corriente Clasista y Combativa y Barrios de Pie.

${ }^{2}$ Así excluyen del proceso de la EP a todo proceso económico de producción, intercambio, financiamiento y consumo con niveles de rentabilidad que les permite un proceso de acumulación y al sector público.

${ }^{3}$ El presidente Duhalde, vía decreto (565/2002), 3 de abril de 2002 sancionó el programa.

${ }^{4}$ Este se fundamentaba en el Artículo 75, inciso 22 de la Constitución de la Nación, que reconoce el derecho familiar a la "inclusión social», cuyo fin primordial es "asegurar un ingreso mínimo mensual a todas las familias argentinas."

5 Esto era en el marco del "Plan Federal de Emergencia Habitacional" (2003), y otros programas como "Agua más Trabajo", "Obra Pública Municipal", "Centros Integradores Comunitarios". 6 Este estaba orientado a mujeres preferentemente con tres o más hijos a cargo, menores o discapacitados que percibieran la Asignación Universal por Hijo y/o que sufrieran violencia de

género. Suponía la versión con perspectiva de género del PRIST en tanto promovía la participación comunitaria para el mejoramiento de la infraestructura urbana a la vez que instaba a la terminalidad educativa "a fin de mejorar su empleabilidad, estima y reconocimiento familiar». ${ }^{7}$ En un contexto de crisis internacional, las políticas neo desarrollistas se orientaban por crear un conjunto de baterías para inyectar dinero al mercado interno y garantizar no solo el ingreso sino el sostenimiento del consumo. Este programa puede ser no solamente analizado desde su declarada intención de formar empleo sino una vía por la cual los sectores más pobres podían seguir en el mercado de consumo. Como se señalará también sirvió para generar circuitos monetarios de los mercados secundarios o "populares".

${ }^{8}$ Hasta que en el año 2016 lo cambia el gobierno de Mauricio Macri. El principal cambio realizado por el gobierno posterior al 2015 fue la colectivización del trabajo que este suponía.

9 Después del 2015, la Confederación de Trabajadores de la Economía Popular pudo devenir en Ente Ejecutor.

${ }^{10}$ Entrevista a Mariela, desocupada que participa del Movimiento de Trabajadores Desocupados Aníbal Verón realizada en junio del año 2004.

11 Entrevista realizada a un dirigente del MTD A. v. (07.2004). 
12 Entrevista a desocupado militante de la Corriente Clasista y combativa realizada en octubre del año 2004.

13 Palabras pronunciadas por el secretario general de la Confederación de Trabajadores de la Economía Popular, Esteban Castro, frente a la declaración del inicio de la Marcha Federal de mayo de 2018.

${ }^{14}$ Entre ellas, Barrios de Pie, Federación Tierra y Vivienda, Barrios de Pie, el Movimiento de Trabajadores Desocupados Evita (luego corazón del Movimiento Evita)

${ }^{15}$ Entrevista a Esteban Gringo Castro, Secretario General de la CTEP

${ }^{16}$ Esta frase será repetida en diversos espacios y referentes de la CTEP.

${ }^{17}$ El cuadernillo denominado "Nuestros ObjetiVos" (2014) es publicado bajo los nombres de los principales referentes de la CTEP Pérsico del Movimiento Evita y Grabois del Movimiento de Trabajadores Excluidos. En el mismo se declaran estos objetivos. Como se analizará más adelante estas demandas específicas fueron tramitadas de forma parcial: el salario social complementario sería aprobado en conjunto con la paritaria popular en el año 2016 como se analizara en las siguientes secciones. El Ministerio de Economía Popular fue parte de la plataforma del candidato Daniel Scioli que perdió frente a Macri en las elecciones de 2015. Para ampliar sobre las acciones colectivas de la CTEP ver Muñoz y Villar, 2017.

${ }^{18}$ En el año 2016, con el gobierno de Macri se firmó el Plan Nacional de Economía Social "Creer y Crear". El plan tiene como objetivo impulsar el desarrollo local y regional a través del apoyo a emprendimientos que promuevan la inclusión social y productiva de las personas. Este lenguaje retorna a la dimensión del "emprendedor" que le asigna la principal responsabilidad de generación de trabajo a la persona afectada. En palabras de la ministra Carolina Stanley «Esta es una manera de acompañarlos y acercarles la posibilidad de capacitarse y de emprender, según la economía de su provincia. De este modo, se potencia el crecimiento individual y también el regional». El
Estado acompaña, pero no es responsable. No disponemos datos de ingreso al programa.

19 De acuerdo a la ley, los montos deben ser equivalentes al 50\% del Salario Mínimo, Vital y Móvil (para septiembre del 2017 sería de 8.860 pesos). Estas asignaciones estaban retrasadas desde el 1 de julio, y se volvieron a incrementar de acuerdo a resoluciones del MTEySS en septiembre. En el mes de octubre el Salario Social Complementario alcanzaría 4400 pesos, a lo que se debería sumar lo que cobra la familia por la AUH.

${ }^{20}$ Es interesante señalar cómo la articulación supone una instancia singular de construcción de identidades políticas que no se expresa solo en la producción lingüística sino de estrategia política. Por ejemplo, en el año 2017, en la Federación Universitaria de La Plata se creó un frente de organizaciones denominado "Frente Estudiantil 7 de Agosto", por la fecha donde se generó la marcha de San Cayetano. Las agrupaciones sostienen que tiene que ver con el símbolo que se produjo al marchar "todos juntos contra Macri", reconociendo a «los trabajadores de la economía popular" como trabajadores que son parte de la unidad en la lucha.

${ }^{21} \mathrm{Al}$ momento de redactarse este artículo se producen dos hechos que implican mayor articulación de estas organizaciones. La primera es la organización de una marcha "federal" impulsada por el Triunvirato de los Trabajadores de la Encomia Popular para presentar cinco proyectos de ley, la CGT y las CTAs. La segunda es un conjunto de organizaciones lanzo un frente político denominado "Vamos" integrado por el Movimiento Libres del Sur, Unidad Popular, y el Movimiento Evita, entre otros. Este se presenta como una alianza para competir para las elecciones de presidente de 2019. Además, se han generado una serie de propuestas programáticas desde las organizaciones sociales CTEP, Barrios de Pie y CCC que se expresan como proyectos de ley. Entre las más relevantes se encuentra la que propone que el $25 \%$ de las obras públicas se destine a las cooperativas y a los trabajadores de la economía popular. 


\section{BIBLIOGRAFÍA}

Adelantado, J., J. Noguera, X. Rambla y L. Saez. (1998) "Las relaciones entre estructura y políticas sociales: una propuesta teórica", Revista Mexicana de Sociología, 60 (3), pp. 123-156.

Altvater, Elmar (2014) "El fin del capitalismo tal como lo conocemos». En Giarracca, N. y Massuh, G. (Comps.) El trabajo por venir. Autogestión y emancipación social, Buenos Aires, Editorial Antropofagia.p 17-32

Antía, F. (2017). "Regímenes de política social en América Latina: una revisión crítica de la literatura.» En Desafíos. Disponible en: http://dx.doi.org/10.12804/revistas.urosario.edu.co/ desafios/a.4802 (consultado 20-05-2018)

Antunes, R. (1999) ¿Adiós al trabajo? Ensayo sobre las metamorfosis y el rol central del mundo del trabajo. Buenos Aires, Antidoto.

Arakaki, A. (2017). "Movilidad ocupacional en un mercado de trabajo segmentado. Argentina, 2003-2013", Estudios del Trabajo, (14), Julio-Dic. Pp 27-54

Arango, Y., Yudy, A.; Chena, P.I.; Roig, A. (2017). "Trabajo, ingresos y consumos en la economía popular», Cartografías del Sur. Revista Multidisciplinaria en Ciencias, Arte y Tecnología de la Universidad Nacional de Avellaneda, (6), pp. 1-18

Arcidiácono, A. y Bermúdez, Á. (2017). “La expansión del cooperativismo de trabajo bajo programas. Una mirada sobre el Programa Ingreso Social con Trabajo- Argentina Trabaja». En Pautassi, L. y Gamallo, G. (coord.). El bienestar en brechas: un análisis de las políticas sociales en la Argentina de la posconvertibilidad. Buenos Aires: Biblos. pp. 137-167. 
Arcidiácono, M. (2015). "Salario mínimo y distribución salarial: evidencia para Argentina, 2003-2013", Documentos de Trabajo del CEDLAS. La Plata: Universidad Nacional de La Plata. Disponible en: http://sedici.unlp.edu.ar/bitstream/handle/10915/51681/Documento_completo__.pdf?sequence $=1$ (consultado 20-08-2017)

Arcidiácono, P. y Zibecchi, C. (2017). La trama de las políticas sociales. Estado, saberes y territorio. Buenos Aires: Biblos.

Arcidiácono, P., Kalpschtrej, K., Bermúdez, Á. (2013). “¿Transferencias de ingresos, cooperativismo o trabajo asalariado? El Programa Argentina Trabaja", Trabajo y Sociedad, 22, pp. 341-356. Disponible en: www.unse.edu.ar/trabajoysociedad (Consulta 1/2/2016).

Barbosa, R.N. (2007). Economia solidaria como política pública tendência de gene ração de renda e ressignificação do trabalho. São Paulo: Cortez.

Becher, Y. (2017). "Políticas sociales y subjetividad Un análisis socio-histórico sobre la concepción de sujeto", KAIROS. Revista de Temas Sociales. (21) 39. Disponible en http:// www.revistakairos.org/politicas-sociales-y-subjetividad-un-analisis-socio-historico-sobre-laconcepcion-de-sujeto/ Consultado (Consultado 10/12/2017)

Bertranou, Fabio M. y Paz, J.A. (2007). Políticas y programas de protección al desempleo en Argentina. Buenos Aires: Oficina Internacional del Trabajo. Disponible en http://ilo.org/wcmsp5/ groups/public/---americas/---ro-lima/---sro-santiago/documents/publication/wcms_180859. pdf (Consultado 13/05/2017)

Bialakowsky, A. y Hermo, J.P. (2015). "Repensar la sociología del trabajo desde el Sur Global Nuevos y viejos desafíos para comprender los procesos sociales de trabajo en el capitalismo globalizado", Revista Mexicana de Ciencias Políticas y Sociales. Año LX, 224. pp. 45-70

Bona, L., Palmieri, P. Chena, P. y Sbatella, J.A. (2012). Origen, apropiación y destinos del excedente económico en la Argentina de la posconvertibilidad. Buenos Aires. Colihue. Buenos Aires: UNGS. Pp. 311-363

Bustos, J.M. y Molina, M. (2016). “Economía Social. Descripción y caracterización del sector y principales hallazgos de la investigación cualitativa." Presentación en el Segundo Taller de la Subsecretaría de Políticas, Estadísticas y Estudios Laborales del Ministerio de Trabajo, Empleo y Seguridad Social.

Bustos, J.M. y Trujillo, L. (2014) “Protección social y trabajo infantil en Argentina», en AA.VV., Trabajo infantil en la Argentina. Políticas públicas y desarrollo de experiencias sectoriales y locales, Buenos Aires, OIT, Ministerio de Trabajo, Empleo y Seguridad Social, UNICEF.

Cechini, S. y Madariaga, A. (2011) Programa de transferencias condicionadas. Balance de la experiencia reciente en América Latina y el Caribe. Cuadernos N 95 CEPAL. 
Centro de Investigaciones Socio-económica de Buenos Aires (CISBA) (2015) «Informe técnico y resultados de la encuesta sobre deuda e ingresos en los sectores populares.". Buenos Aires, Argentina.

CESO (2017). "Economía Popular y Trabajo Crecimiento de la Importación de Alimento en Argentina". En Informe de la Economía Popular, Nro. II, Septiembre. Disponible en http://www. ceso.com.ar/informe-economia-popular-ndeg-iii-octubre-2017

Coraggio, L. (2015). Miradas sobre la economía social y solidaria en América Latina. Los Polvorines: Universidad Nacional de General Sarmiento.

(2016). "La economía social y solidaria (ESS): niveles y alcances de acción de sus actores. El papel de las universidades". En Puig, Carlos (coord.) Economía Social y Solidaria: conceptos, prácticas y políticas públicas Bilbao: España. Pp 15 - 41

Cortés, R. y Kessler, G. (2013). "Miradas sobre la cuestión social en la Argentina democrática (1983-2013)». Cuestiones de Sociología, No 9. P. 33-55

Cortes, R. y Marshall, A. (1991) “Estrategias económicas, intervención social del Estado y regulación de la fuerza de trabajo. Argentina 1890-1990", Estudios de Trabajo, 1, 21-49.

Costa, M.C., Deux Marzi M.V. y Hintze, S. (2011). “Los organismos públicos de promoción del trabajo asociativo autogestionado en la Argentina». En Danani, C. y Hintze, S. (coord.). (2011). Protecciones y desprotecciones: la Seguridad Social en la Argentina 1990-2010. Buenos Aires: UNGS. Pp. 233-281

Cruces, G. y Gasparini, L. (2008). "Programas Sociales en Argentina: Alternativas para la Ampliación de la Cobertura". En CEDLAS. Documento de Trabajo Nro. 77 Disponible en: http:// sedici.unlp.edu.ar/bitstream/handle/10915/3636/Documento_completo.pdf?sequence=1 Consultado $(17 / 04 / 2016)$

Danani, C y Hintze, S. (coord.). (2014). Protecciones y desprotecciones: problemas y debates sobre la seguridad social en Argentina. Buenos Aires: UNGS.

Delamata, G (2005) "Las organizaciones de desocupados del Gran Buenos Aires y la (s) crisis." En Schuster, F. et al (comp) Tomar la Palabra. Estudios sobre la protesta social y la acción colectiva en la Argentina contemporánea. Buenos Aires: Prometeo. Pp. 365 - 387.

Denning Michael, (2011). "Vida sin salario", New Left Review, (66), pp. 77-94

Deux Marzi M.V. y Hintze, S. (2014). «Protección y seguridad social de los trabajadores asociativos autogestionados" Danani, C y Hintze, S. (coord.). (2014). Protecciones y desprotecciones: problemas y debates sobre la seguridad social en Argentina. Buenos Aires: UNGS.

Esping Andersen, G. (1993) Los tres mundos del Estado de Bienestar, Alfous El magnanim Edicions, Generalitat Valenciana, Págs. 37-50 
Fernández Álvarez, M.I. (2016). Hacer juntos (as) dinámicas, contornos y relieves de la política colectiva. Buenos Aires: Editorial Biblos.

Godio, J. (2003). Argentina. Luces y Sombras en el primer año de transición. Buenos Aires: Editorial Biblos.

Goldbert, L. (2004). «¿Derecho a la inclusión o paz social? Plan Jefas y Jefes de Hogar Desocupados". En Serie Conferencias y Seminarios: Gestión y financiamiento de las políticas que afectan a las familias. Buenos Aires: UNFPA, Naciones Unidas y CEPAL.

Grabois, J. (2017) La Personería Social, Buenos Aires, Universidad de Derecho.

Grabois, J. y Pérsico, E. (2014). Organización y economía popular: nuestros objetivos. Buenos Aires: CTEP - Asociación Civil de los Trabajadores de la Economía.

Gracia, M.A. (2015). Trabajo, reciprocidad y re producción de la vida. Experiencias colectivas de autogestión y economía solidaria en América Latina. Buenos Aires: Mino y Dávila Editores.

Graña, J.M. (2013). Las condiciones productivas de las empresas como causa de la evolución de las condiciones de empleo. La industria manufacturera en Argentina desde mediados del siglo XX. Universidad de Buenos Aires, Buenos Aires.

Grassi, E (2012). "La política social y el trabajo en la Argentina contemporánea: entre la novedad y la tradición". e-l@tina Revista electrónica de estudios latinoamericanos,vol. 10, $n^{\circ}$ 39. Abril-junio. Instituto de Estudios de América Latina y el Caribe (lealc).

Groisman, F. (2016). Estructura social e Informalidad Laboral en Argentina. Buenos Aires; Eudeba.

Hintze, S. (2010). La política es un arma cargada de futuro: La economía social y solidaria en Brasil y Venezuela. Buenos Aires. CLACSO

Hopp, M. (2017) "Transformaciones en las políticas sociales de promoción de la economía social y del trabajo en la economía popular en la Argentina actual.», Cartografías del Sur, N6, Diciembre. pp

Hopp, M.V. (2016). «Potencialidades y límites del programa Argentina en dos barrios ppulares del conurbano bonaerense", Documentos y Aportes en Administración Pública y Gestión Estatal DAAPGE, (27) , pp. 7-35

Hudson, J.P. (2017). "Gobiernos progresistas y autogestión en la Argentina 2003-2015: cooperativas no-estatales, sintéticas y anfibias", Revista Latinoamericana de Estudios del Trabajo, () p. 91-122.

Lavopa, A. (2007). "La Argentina posdevaluación ¿un nuevo modelo económico?», Realidad Económica, (231), pp. 48-73. 
Maldovan, J., Bonelli, Y. Mouján, Fernández. F; Moler, E. (2017), «Políticas públicas e instituciones de regulación socio-laboral para la Economía Popular. Supuestos y tensiones en el debate por la ley de Emergencia Social.» Documento disponible en http://www.aset.org. ar/2017/ponencias/14_Maldovan.pdf (Consultado 10/10/2017)

Manzano, V. (2013). La política en movimiento. Movilizaciones coelctivas y políticas estatales en la vida del Gran Buenos Aires. Rosario: Prohistoria Ediciones.

Mariotti, Daniela et al. (2007). Tiempos de rebelión: "Que se vayan todos". Buenos Aires: Antropofagia.

Massetti, A. (2004) Piqueteros. Protesta social e identidad colectiva. Buenos Aires: Editorial de las Ciencias. Flacso.

Merklen, D. (2005) Pobres ciudadanos. Las clases populares en la era democrática (Argentina 1983-2003), Buenos Aires: Gorla.

Messina, G. M. (2017). «La ilusión trabajo-céntrica: contra adicciones del régimen de bienestar argentino bajo el kirchnerismo", Trabajo y Sociedad. (29) Inv. pp.583-610

Ministerio de Trabajo, Empleo y Seguridad Social - MTESS (2018). «Reporte del Trabajo Registrado". Disponible en: http://www.trabajo.gob.ar/downloads/estadisticas/Reporte_trabajo_Mayo_2018.pdf (Consultado: 31/05/2018)

Muñoz, M.A. (2004). "Los discursos de la desocupación y la pobreza, las organizaciones de desocupados y la esfera político estatal", Lavboratorio, 4 (15), Disponible en: https://catedracoi2.files.wordpress.com/2013/06/muc3b1oz-antonia-los-discursos-de-la-desocupacic3b3ny-la-pobreza-las-organizaciones-e280a6.pdf (Consultado 15-06-2009)

(2005), "La difícil construcción de una identidad colectiva: Los piqueteros", AlBR. Revista de Antropología Iberoamericana, (43), septiembre-octubre.

- (2009), "Crisis política y conflicto social en Argentina. Alcances y límites de un tipo de participación política no convencional», Review of Latin American and Caribbean Studies, (87), pp.63-92.

(2010). Sísifo en Argentina. Orden Conflicto y sujetos políticos. México: Editorial Universitaria Villa María, Plaza y Valdés.

(2017). "La(s) violencia(s) y la democracia como conceptos co-dependientes: el caso argentino", Revista Athenea Digital, N 17(2), p. 3-30.

Muñoz, M.A. y Villar, L.I. (2017) «Confederación de Trabajadores de la Economía Popular (CTEP en la CGT). Entre la organización sindical y el conflicto político-social (Argentina, 2011-2017)", Crítica y Resistencias. Revista de conflictos sociales latinoamericanos, (5), Pp. 22-52. 
Narodowski, P (2013). «Economía popular. Una estrategia para sostener la actual alianza política y profundizar el cambio estructural", Realidad Económica (279), Octubre / Noviembre, Pp. 100-131

Neffa, J.C., Oliveri, M.L. y Persia, J. (2010). "Transformaciones del mercado de trabajo en Argentina: 1974-2009.» Atlántida. Revista Canaria de Ciencias Sociales, (2), pp. 19-48

Niedzwiecki, N. y Pribble, J. (2017). "Social Policies and Center-Right Governments in Argentina and Chile." Latin American Politics and Society, 59(3), pp. 72-97.

Novick, M. (2016). "Con la gente adentro. Que se logró (y que quedó pendiente) en materia de empleo, equidad y justicia Social», En Filmus (comp.). Pensar el Kirchnerismo. Lo que se hizo, lo que falta y lo que se viene. Buenos Aires: Siglo XXI.

Nun, J. (2010). "Sobre el concepto de masa marginal». Revista de estudios sobre cambio estructural y desigualdad social -Lavboratorio-, (23), pp. 109-119.

Observatorio de Empleo, Producción y Comercio Exterior (ODEP) (2018). "Síntomas de Precarización del Mercado Laboral». Buenos Aires: UMET Disponible en: http://umet.edu. ar/nuevo-informe-del-odep-la-umet/ Consultado (30/05/2018)

Palomino, H. y Trajtemberg, D. (2006). "Una nueva dinámica de las relaciones laborales y la negociación colectiva en la Argentina", Revista de Trabajo, N2 (3), pp. 47-68.

Pérsico, E., F. Navarro, M., Navarro, A., Geandet, A., Roig y P. Chena, (2017) Economía Popular. Los desafíos del trabajo sin patrón. Bs. As.: Colinue.

Quijano, A. (2000). "Colonialidad del poder y clasificación social», Journal of World-Systems Research, N 6 (2) pp. 342-386.

Quijano, Anibal, (1992) Colonialidad del poder. Eurocentrismo y América Latina. Lima, Amauta.

Retamozo, M. (2006), El movimiento de trabajadores desocupados en Argentina. Subjetividad y acción en la disputa por el orden social. Mimeo. Tesis de Doctorado. FLACSO, México.

Retamozo, M. y Morris, B. (2015). "Sindicalismo y Política. La Central de Trabajadores Argentinos tiempos kirchneristas", Estudios Sociológicos. N33 (97). P 6388

Roconi, L. (2002). "El programa Trabajar», Documentos Centro de Estudios para el Desarrollo Institucional UDESA, (63), Marzo Disponible en: http://faculty.udesa.edu.ar/Tommasi/cedi/dts/ dt63.pdf (Consultado 13/05/2012)

Roig, A. (2015) «Separar de sí, separar para sí: las prácticas de ahorro domésticas en sectores populares urbanos argentinos". En Wilkis \& Roig. El laberinto de la moneda y las finanzas. Buenos Aires. Editorial Biblos. 
Seiffer, T y Rivas Castro, G. (2017). "La política social como forma de reproducción de la especificidad histórica de la acumulación de capital en Argentina (2003-2016)", Estudios del trabajo, Julio Diciembre, (54). Pp 91 - 117.

Soldano, D. y L. Andrenacci (2005) "Aproximación a las teorías de la política social a partir del caso argentino". En L. Andrenacci (comp.) Problemas de política social en la Argentina contemporánea, Buenos Aires, Argentina, Prometeo, pp. 17-79.

Stein, R.H. (2017). «La protección social en América Latina y la particularidad de la asistencia social", SER Social, v. 19, (40), pp. 49-68.

Svampa M. y Sebastián, P. (2003), Entre la ruta y el barrio. La experiencia de las organizaciones piqueteras. Buenos Aires: Biblos.

Svampa, M (2005). La sociedad excluyente. La Argentina bajo el signo del neoliberalismo. Buenos Aires: Taurus.

Trujillo, L, y Retamozo, M. (2017), "Economía política de la desigualdad en Argentina (2003-2015). Instituciones laborales y protección social», Temas debates, (33), pp.35-61.

Trujillo, L. (2017), "Los determinantes de la desigualdad del ingreso: El rol del mercado de trabajo, de las instituciones laborales y la protección social. Un estudio a través de descomposiciones de los índices de GINI y de Theil en Argentina (2003-2014)", Tesis de Doctorado, Facultad de Humanidades y Ciencias de la Educación, Universidad Nacional de La Plata

Varesi, G.Á. (2016). "Gobierno de Macri en sus primeros meses", en Realidad económica, (302), pp 6-34.

Vio, M. y Cabrera, M.C. (2015). “La trama social de la economía popular en el Conurbano bonaerense", Revista E versión digital, (5), pp. 60-67.

\section{PARA CITAR ESTE ARTÍCULO:}

Muñoz, M.A. (2018). "Las marcas de los sujetos en el Estado. Los trabajadores de la economía popular y las políticas públicas en la Argentina recienten, DAAPGE, año 18, № 30 (ene-jun), 2018, pp. 85-128. Santa Fe, Argentina: UNL. 